\title{
Quantification of transport across the boundary of the lower stratospheric vortex during Arctic winter 2002/2003
}

\author{
G. Günther ${ }^{1}$, R. Müller ${ }^{1}$, M. von Hobe ${ }^{1}$, F. Stroh ${ }^{1}$, P. Konopka ${ }^{1}$, and C. M. Volk ${ }^{2}$ \\ ${ }^{1}$ Institute for Chemistry and Geodynamics (ICG-1), Forschungszentrum Jülich, 52425 Jülich, Germany \\ ${ }^{2}$ Institute for Meteorology and Geophysics, Universität Frankfurt, 60325 Frankfurt, Germany
}

Received: 13 November 2007 - Published in Atmos. Chem. Phys. Discuss.: 4 December 2007

Revised: 4 March 2008 - Accepted: 26 May 2008 - Published: 10 July 2008

\begin{abstract}
Strong perturbations of the Arctic stratosphere during the winter 2002/2003 by planetary waves led to enhanced stretching and folding of the vortex. On two occasions the vortex in the lower stratosphere split into two secondary vortices that re-merged after some days. As a result of these strong disturbances the role of transport in and out of the vortex was stronger than usual. An advection and mixing simulation with the Chemical Lagrangian Model of the Stratosphere (CLaMS) utilising a suite of inert tracers tagging the original position of the air masses has been carried out. The results show a variety of synoptic and small scale features in the vicinity of the vortex boundary, especially long filaments peeling off the vortex edge and being slowly mixed into the mid latitude environment. The vortex folding events, followed by re-merging of different parts of the vortex led to strong filamentation of the vortex interior. During January, February, and March 2003 flights of the Russian high-altitude aircraft Geophysica were performed in order to probe the vortex, filaments and in one case the merging zone between the secondary vortices. Comparisons between CLaMS results and observations obtained from the Geophysica flights show in general good agreement.

Several areas affected by both transport and strong mixing could be identified, allowing explanation of many of the structures observed during the flights. Furthermore, the CLaMS simulations allow for a quantification of the air mass exchange between mid latitudes and the vortex interior. The simulation suggests that after the formation of the vortex was completed, its interior remaind relatively undisturbed. Only during the two re-merging events were substantial amounts of extra-vortex air transported into the polar vortex. When in March the vortex starts weakening additional influence from lower latitudes becomes apparent in the model results.
\end{abstract}

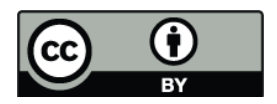

Correspondence to: G. Günther (g.guenther@fz-juelich.de)
In the lower stratosphere export of vortex air leads only to a fraction of about $5 \%$ polar air in mid latitudes by the end of March. An upper limit for the contribution of ozone depleted vortex air on mid-latitude ozone loss is derived, indicating that the maximum final impact of dilution is on the order of $50 \%$.

\section{Introduction}

The Arctic polar vortex in 2002/2003 was unusual in so far as low temperatures, below the threshold for Polar Stratospheric Cloud (PSC) formation, chlorine activation and ozone loss occurred very early already in mid December 2002 (Tilmes et al., 2003a; Goutail et al., 2005). From end of December on, polar temperatures increased and the potential for chlorine activation was strongly reduced after mid January. This picture is corroborated by PSC observations showing high PSC occurence in the first three weeks of December, moderate PSC activity in early January, sporadic and weak PSC events in February and March (Spang et al., 2005). The early onset of ozone depletion is also reproduced by model simulations (Grooß et al., 2005; Goutail et al., 2005). There was a moderate chemical ozone loss in this winter, ozone loss values reported for March 2003 for the lower stratosphere range between $\approx 40$ DU to more than 50 DU (Tilmes et al., 2003b; Christensen et al., 2005; Goutail et al., 2005; Müller et al., 2007). A somewhat greater chemical ozone loss of $56 \mathrm{DU}$ for the partial ozone column between 400 and $500 \mathrm{~K}$ potential temperature for the period from the beginning of December to mid March is reported by Streibel et al. (2006) based on the Match technique.

During winter 2003 the Arctic vortex split and re-merged twice, once in January and once in Februrary. Small scale filamentary structures were produced in the composition of the vortex air by these two split events. Air from outside the vortex was enclosed by the vortex due to repeated folding

Published by Copernicus Publications on behalf of the European Geosciences Union. 
and remerging, thus disturbing the isolation of the vortex and creating adjacent areas of air of completely different origin. The effect of in-mixing events on deducing chemical ozone loss inside the polar vortex has been discussed in Grooß et al. (2008), indicating that the consideration of these events generally leads to lower estimates of ozone loss.

Additionally, the export of ozone depleted or chemically activated air from the polar vortices has an effect on the ozone abundance in the mid-latitude stratosphere in spring and summer. It is important to quantify the extent of the export of processed vortex air to mid-latitudes to assess the relevance of this process for the observed ozone trends in mid-latitudes (WMO, 2007) compared to chemical destruction of ozone in the mid-latitudinal air masses themselves. Model studies have been conducted to quantify this effect (e.g, Knudsen and Grooß, 2000; Hadjinicolaou and Pyle, 2004; WMO, 2007). In the Arctic, there is a large yearto-year variability of the impact of polar processes on midlatitudes, but contributions of vortex air to mid-latitude ozone loss of up to 25 DU have been reported (Millard et al., 2002). On several occasions remnants of vortex air in the Northern Hemisphere mid-latitudes have been observed and have been reproduced in model simulations (Orsolini, 2001; Konopka et al., 2003; Manney et al., 2005; Grooß et al., 2008).

The question arises how to quantify the effect of these processes on the composition and chemsitry of the polar vortex and the mid-latitudes. Morgenstern et al. (2003) proposed a method to quantify air mass origin using the SLIMCAT model and applied it to trace the transport of former polar vortex air into midlatitudes during and after the breakdown of the polar vortex. In this way they were able to diagnose the substantial meteorological differences between the Arctic winters 1999/2000 and 2000/2001, where the vortex 1999/2000 was extremely long-lived leading to the production of vortex "fossils" that remain noticeable until early June 2000, whereas the dilution of vortex air in mid-latitudes in 2000/2001 was much faster.

Here we employ simulations with the Chemical Lagrangian Model of the Stratosphere (CLaMS) (McKenna et al., 2002a,b) to investigate transport through mixing in the dynamically very active situation in winter 2002/2003. The permeability of the Arctic polar vortex edge has been studied previously with CLaMS by using artificial tracers that are initialized in the vortex as $100 \%$ and zero outside (Steinhorst et al., 2005). Here we extend this concept by considering a whole set of tracers of air mass origin. The mixing scheme in CLaMS allows the evolution of the spectrum of air mass origin for every single air parcel in the model to be followed.

An advantage of this technique is that averages of air-mass origins over selected regions may be deduced that are based on the information of the mixture of air-mass origin in each single air parcel in the model. In so far, our model concept is similar, but not identical to the concept of air mass origin put forward by Morgenstern et al. (2003).
During winter 2002/2003 the European field campaign "European Polar Stratospheric Cloud and Lee Wave Experiment" (EUPLEX) was carried out as a part of VINTERSOL ("Validation of International Satellites and Study of Ozone Loss").

The campaign took place from mid January to mid February 2003 in Kiruna, Sweden, utilising the high flying Russian aircraft Geophysica for stratospheric in-situ measurements. Directly connected to this campaign was an ENVISAT validation phase, carried out between the end of February and mid March with very similar instrumentation. The measurements obtained during both, EUPLEX and the ENVISAT validation, showed indications of strong filamentation in and outside the lowest part of the Arctic polar vortex. To help with the interpretation of the observations, to investigate the influence of the observed small scale structures on the composition of the lower vortex and to estimate the cross boundary flux, simulations with the CLaMS model are used.

Information on air mass origin and mixing from observations is provided by the measurements of long lived tracers. During EUPLEX in-situ tracer measurements were performed by the gas chromatograph HAGAR (High Altitude Gas Analyzer, Riediger et al., 2000). Methane $\left(\mathrm{CH}_{4}\right)$ observations used in this study were made with a time resolution of $90 \mathrm{~s}$ and a mean precision of $2 \%$. In-flight calibrations were carried out with two standards linked to within $1 \%$ of the NOAA-CMDL scale.

To aid the detection and characterisation of small scale dynamical features that are not resolved with the HAGAR time resolution, in-situ $\mathrm{ClO}$ measurements are used in addition. These were made by the HALOX instrument described in detail by von Hobe et al. (2005). It employs the chemical conversion resonance fluorescence technique (Brune et al., 1989 ) and measures $\mathrm{ClO}$ with an accuracy of $16 \%$, a precision of $8 \%$ and a time resolution of $10 \mathrm{~s}$ under conditions of high $\mathrm{ClO}$ caused by chlorine activation in the vortex.

Because $\mathrm{ClO}$ is affected by chemical processes on much shorter timescales than the rather inert long lived tracers, it is not suited as a quantitative tracer. However, as long as significant and not too inhomogeneous chlorine activation prevails within the polar vortex and under daylight conditions, the contribution of vortex air to the probed air masses can be identified qualitatively by elevated $\mathrm{ClO}$ levels. This was the case throughout the EUPLEX and ENVISAT Arctic Validation campaigns although the signal gets weaker towards the end of the winter as chlorine becomes increasingly deactivated.

A description of the CLaMS model and the tracer suite to create air mass origin spectra can be found in the next section. A short analysis of the dynamics of the Arctic lower stratosphere during January, February, and March 2003 will be given in Sect. 3. Measurements of $\mathrm{CH}_{4}$ and $\mathrm{ClO}$ obtained during the EUPLEX and ENVISAT validation experiments are used to evaluate the model results and discussed in Sect. 4. A comparison between observations and model 
results will follow in Sect. 5 to validate the CLaMS model. The results of the simulation utilizing the suite of inert tracers will then be used to quantify the effects of transport and mixing on the composition of the polar vortex and the midlatitudes.

\section{Model description}

We use the Chemical Lagrangian Model of the Stratosphere (CLaMS) (McKenna et al., 2002b,a; Konopka et al., 2004, 2007) for a numerical simulation focusing on dynamical aspects like advection and mixing for this unusual Arctic winter episode. CLaMS consists (among others) of a trajectory model for the simulation of advection processes, combined with a mixing module which parameterises the results of mixing processes. The intensity of mixing is controlled by the finite time Lyapunov exponent and thus by the deformation of the flow (Konopka et al., 2005).

The CLaMS simulation discussed here uses a new vertical coordinate, the hybrid potential temperature first described by Mahowald et al. (2002). The hybrid potential temperature levels are close to pressure levels below $100 \mathrm{hPa}$. Above 100 $\mathrm{hPa}$ the hybrid potential temperature levels are identical to the conventional potential temperature surfaces. The passage from pressure to potential temperature surfaces is smoothed by using a sinus function. A more detailed description of this model version can be found in Konopka et al. (2007). For all figures and analyses the values of the hybrid potential temperature are converted into potential temperature.

The simulation was limited to the Northern Hemisphere between 300 and $850 \mathrm{~K}$ potential temperature, and started on the 1st of December, 2002, with a mean resolution of $70 \mathrm{~km}$ in the horizontal and $8 \mathrm{~K}$ in the vertical direction. All model boundaries were updated every $6 \mathrm{~h}$ according to the ECMWF operational analyses used to drive the model. The simulation ended on 31st March 2003.

Usually the identification of air masses and their motion and original positions is straight forward when a trajectory model is used. However, the mixing algorithm of CLaMS leads to merging of adjacent air masses or the creation of new air parcels, so that the direct identification of the origin of air masses as in a pure trajectory model is not possible. This problem can be obviated by the use of artificial tracers, that mark particular regions in the atmosphere (e.g. polar or tropical air) at the beginning of the simulation. These artificial inert tracers are then advected and mixed through the course of the simulation by the CLaMS transport scheme. This procedure does not only allow the tracking of air masses as in a trajectory model, but goes beyond as it allows to investigate the contribution of air mass origin in every individual CLaMS air parcel.

Thus, to study and quantify both advection and mixing, a whole suite of inert tracers is introduced: Five tracers were initialised according to the modified Potential Vorticity value
Table 1. Initialisation of the inert tracers according to the modified $\mathrm{PV}$ value or the latitude at the original positions of the air masses on 1st December 2002. Values for mPV ranges are taken from Müller and Günther (2003).

\begin{tabular}{ccll}
\hline Inert Tracer & mPV Range & Description & Colour \\
\hline P0 & $-10, \ldots, 10$. & Tropics & Red \\
P1 & $10, \ldots, 14$. & Mid Latitudes & Green \\
P2 & $14 ., \ldots, 18$. & Outer Vortex Edge & Orange \\
P3 & $18, \ldots, 21$. & Inner Vortex Edge & Cyan \\
P4 & $\geq 21$. & Vortex Core & Blue \\
\hline
\end{tabular}

at the original position (see Table 1 for details). Modified PV (mPV), first described by Lait (1994) and later generalised by Müller and Günther $(2003,2005)$ was defined to reduce the vertical dependency of the PV dependent tracers from the exponential increase of PV with height. The mPV values used to distinguish between the different parts of the vortex and mid latitudes or tropics were chosen because they roughly indicate the boundaries between these different compartments of air over the considered altitude range. The tracers referred to in the following as "inert P-Tracers" were initialised with a value of 1 , if the conditions according to their original positions were fulfilled, and with a value of 0 elsewhere. When mixing is triggered in CLaMS, these tracers are mixed, thus preserving information about the interacting air masses and their origins. In this way an air mass origin spectrum for every air parcel is created. For a schematic of the impact of the mixing scheme on the spectrum of individual air masses see Fig. 1.

With the use of these tracers it is now possible to analyse every individual air mass simulated in CLaMS with respect to the mixing it underwent in the course of the simulation. Since the simulation presented here is relatively short (4 months), no time-dependent tracers were used. This could be introduced for longer simulations to obtain further information about the life-cycle of the considered air masses.

\section{The evolution of the polar vortex}

\subsection{Temperature evolution and planetary wave activity}

The Northern Hemisphere winter of 2002/2003 started with very low temperatures below $190 \mathrm{~K}$ in the Arctic lower stratosphere (Fig. 2). During the first half of December, the polar vortex was only slightly disturbed by planetary waves. During the second half of December, in mid January and mid February the perturbation by planetary waves increased strongly (Fig. 3), leading to a warming of the Arctic lower stratosphere (Fig. 2). While in December the perturbation was characterised mainly by a zonal wave number one 

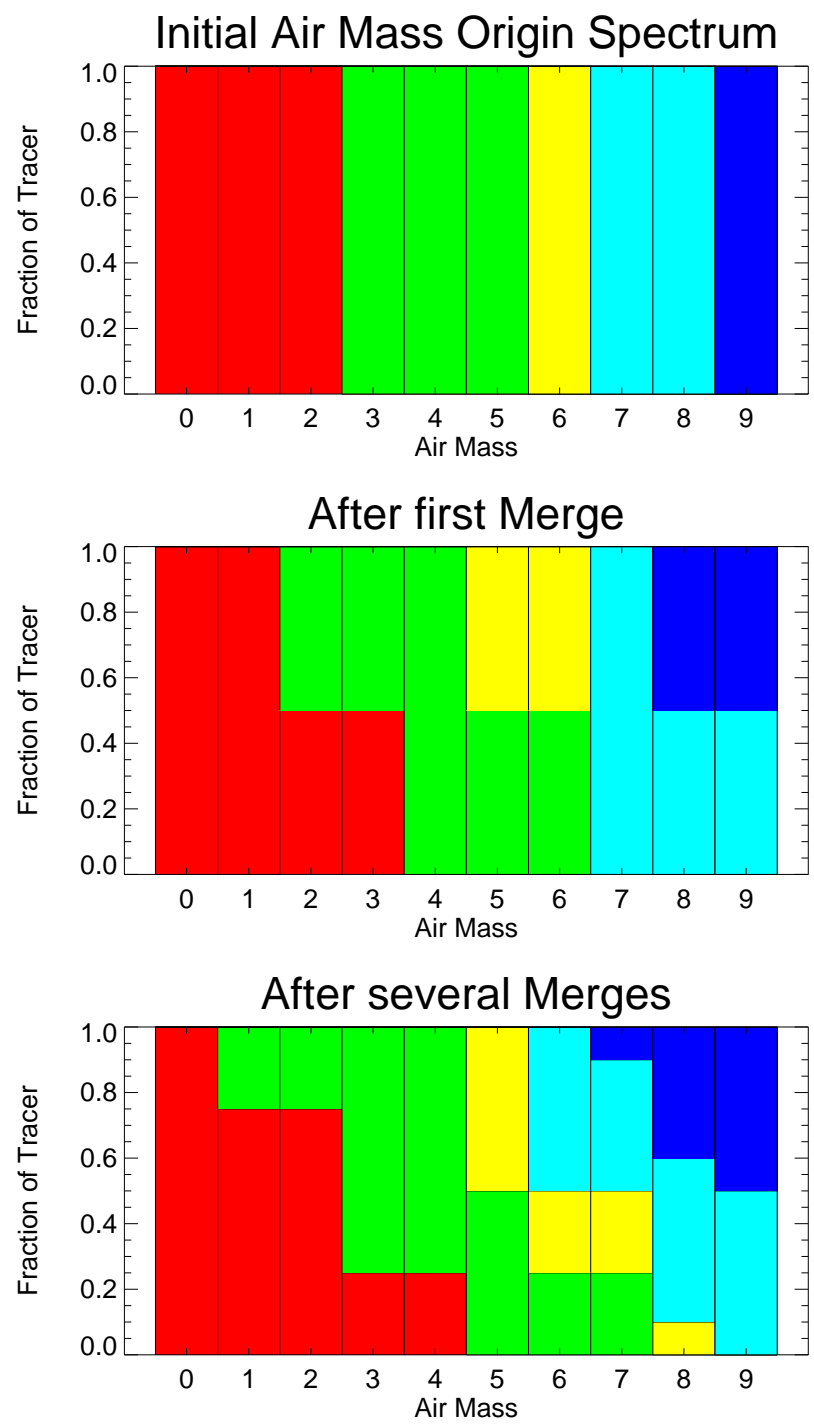

Fig. 1. Schematic of the impact of the CLaMS mixing scheme on the spectrum of air mass origin of individual air parcels. The block diagram shows ten air masses initialised with a suite of inert tracers with respect to the conditions valid at the position at the beginning of the simulation as described in the text. The initialisation is mutually exclusive (upper panel). After the first mixing events, some air parcels contain non-disappearing values of more than one tracer being inherited by their parental air masses in case of merging (middle panel). In this way a spectrum of air mass origin is created in every air mass (lower panel).

pushing the vortex off the north pole, in January and February the dynamics was dominated additionally by a zonal wave number 2 event. During the strong wave breaking events around the 21st of January and the 15th of February the polar vortex split into two secondary vortices which remerged within the next few days (for the splits in January and February see Figs. 4 and 5, respectively). Besides causing vigorous mixing in the vicinity of the vortex edge the

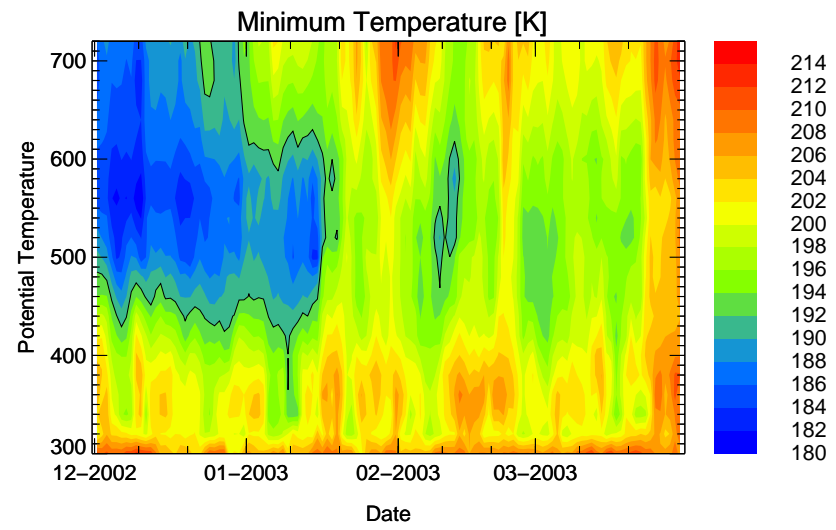

Fig. 2. Temporal evolution of the minimum temperature north of $40^{\circ} \mathrm{N}$ between 1 st December 2002, and 31rd March 2003. The thin black line corresponds to $192 \mathrm{~K}$.

repeating splitting, folding and re-merging led to strong filamentation of the interior of the lower stratospheric vortex with mid latitudinal air masses being folded into the vortex. In turn, the mid latitudes were enriched with air originating from inside the vortex.

The wave number 2 forcing vanished almost completely in March 2003, while the wave number 1 forcing remained as strong as in February, leading to continuous distortion of the lower vortex. As a consequence, the vortex was eroded strongly: big parts of it were cut off the main vortex and mixed into their mid latitudinal environment, thus reducing the vortex-covered area of the Northern Hemisphere (Fig. 6). The transport barrier at the vortex edge weakened significantly, leading to enhanced transport of extra vortex air into the vortex interior.

\subsection{January: the first split of the vortex}

The evolution of the vortex in the lower stratosphere from mid to end of January is shown in Fig. 4 by means of the modified PV (mPV) on the $440 \mathrm{~K}$ level for several days. On 19th January the polar vortex was elongated strongly by the above mentioned perturbations caused by enhanced planetary wave activity. Over northern Canada and Greenland the $\mathrm{mPV}$ gradient was strongly eroded, thus providing a region for air masses from the mid latitudes to enter the vortex area. Air stripped off the outer vortex edge can be seen to wrap around an anticyclonic structure positioned over the northern Pacific, indicating vortex influence in an otherwise mid latitudinal environment.

The lower stratospheric part of the vortex (below $500 \mathrm{~K}$ ) was split into two lobes afterwards (21st January) in between them. According to the ECMWF operational analyses this re-merging zone was then eroded within a few days. Two Geophysica flights (on 23rd and 26th January) were carried out during this episode. Observations obtained on these flights are discussed in the next section. 
At the end of January another wave breaking event led to a deformation of the vortex with a wave number 3 characteristic, transporting low $\mathrm{mPV}$ air deep into the polar regions.

\subsection{February: strong perturbations of the vortex and second split}

The dynamics of the lower stratosphere during February 2003 showed similar features (see Fig. 5). Again the vortex was strongly distorted during the first two weeks of the month, broken up into two secondary vortices on the 17th of February, which re-merged after a few days. This split was different from the first one in January. The two secondary vortices where much more apart and moved more to the south, thus leading to a stronger transport of air from the mid-latitudes into the polar region than in January. In the beginning of this episode, on the 2nd of February, a flight was performed when the polar vortex was located over Kiruna. During this flight filaments of extra vortex air inside the vortex were encountered (see next section).

The second vortex split and re-merging event took place in between the EUPLEX campaign and the ENVISAT validation campaign. Therefore unfortunately no observations are available for this period that would have allowed to analyze similiarities and differnces between the two split events. The first observations available from the ENVISAT validation campaign were made on 28th February.

\subsection{March: the decaying vortex}

During the first half of March the vortex was less disturbed than during the preceding episode (see Fig. 6). Nevertheless, during the second week of March a weak wave number one forcing perturbed the vortex leading to air masses being drawn from the vortex into the mid latitudes, but not being separated completely from the vortex interior. In the framework of the ENVISAT validation campaign five flights were performed during this late stage of the decaying vortex. In the next section we show the observations for the flight on 28th February .

All observations made during EUPLEX suggest that the base of the lower stratospheric vortex was eroded rapidly during the episodes of strongest perturbation during January and February 2003. In between these episodes the vortex seemed to recover, extending its base further downward. The interactions between the vortex and the planetary waves resulted in the generation of flow patterns of small scale both inside and outside the vortex. Some of these were observed during the EUPLEX and the ENVISAT validation campaign.

\section{Observations}

Figure 7 shows the observed mixing ratios of the long-lived tracer $\mathrm{CH}_{4}$ and $\mathrm{ClO}$ along the flight path of the Geophysica on 23rd of January, 2003. This flight was designed to probe
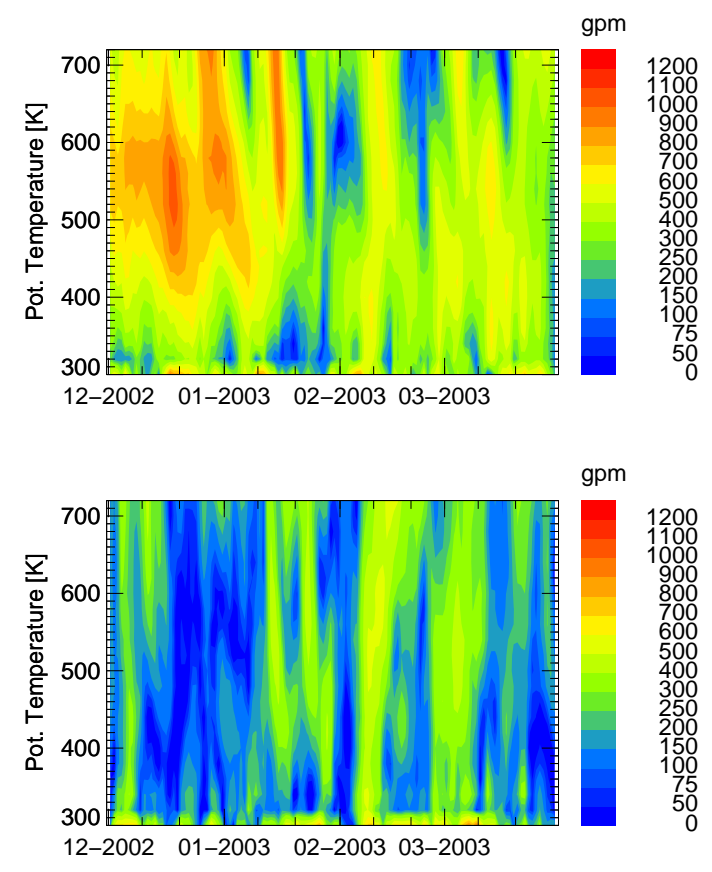

Fig. 3. Temporal evolution of the amplitudes of wave number 1 (upper panel) and wave number 2 (lower panel) between December 1st 2002, and 31rd March 2003, in the lower stratosphere (derived from ECMWF operational analyses).

the re-merging zone of the lower stratospheric vortex. The top panel of this figure displays the evolution of modified PV along the flight path (in PVU and K, respectively), revealing that during the first part of the flight the Geophysica reached the inner vortex edge region and later the lower part of the vortex core (as defined in Table 1). This is in accordance with the observed values of $\mathrm{CH}_{4}$ (centre panel). As a result of the small $\mathrm{CH}_{4}$ gradient inside the vortex, the $\mathrm{ClO}$ observations (centre panel) show the existence of small scale structures more pronounced than $\mathrm{CH}_{4}$. The HALOX observations show that chlorine in the lower part of the vortex at about $430 \mathrm{~K}$ is strongly activated. The observed $\mathrm{ClO}$ distribution as well as $\mathrm{CH}_{4}$ suggests that the Geophysica encounters air from the vortex already during ascent. This is not noticeable in the $\mathrm{mPV}$ values derived from the meteorological data set. Maximum $\mathrm{ClO}$ values were about 500 ppt after about 14:00, for about $30 \mathrm{~min}$, when also enhanced $\mathrm{mPV}$ values and lower methane mixing ratios were observed. After 14:30 the solar zenith angle along the flight path is greater than $100^{\circ}$. Therefore the $\mathrm{ClO}$ variability is not due to photolysis.

The second part of the flight reached the vortex core, where the $\mathrm{CH}_{4}$ values were as low as $800 \mathrm{ppb}$. Again the structures observed in the $\mathrm{ClO}$ distribution are more pronounced than in the $\mathrm{CH}_{4}$ distribution. The structures visible in the $\mathrm{ClO}$ measurements during the second (return) flight leg resemble those in the $\mathrm{mPV}$, that is $\mathrm{ClO}$ decreases as the flight path leads into air masses of lower PV (see also Fig. 4). 


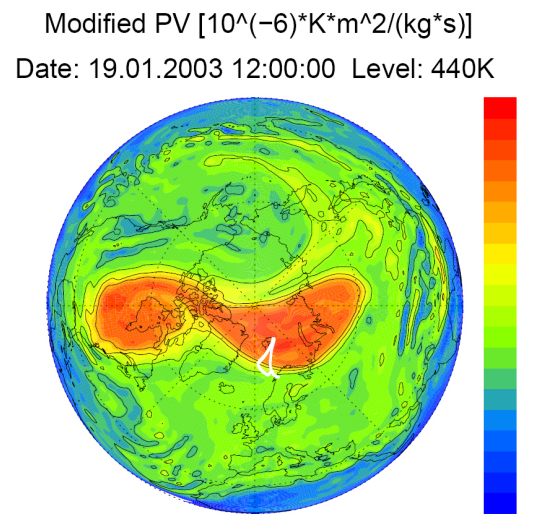

Modified PV $\left[10^{\wedge}(-6)^{\star} \mathrm{K}^{\star} \mathrm{m}^{\wedge} 2 /\left(\mathrm{kg}^{*} \mathrm{~s}\right)\right]$ Date: 22.01.2003 12:00:00 Level: 440K

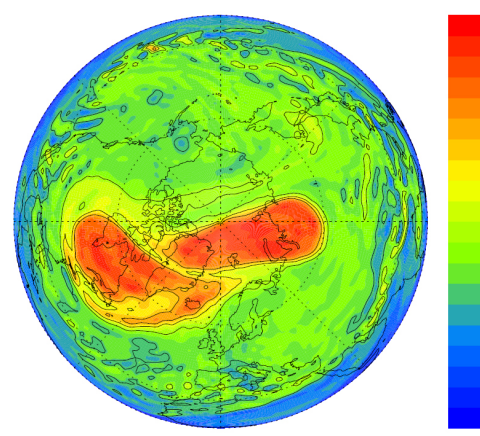

Modified PV $\left[10^{\wedge}(-6)^{\star} \mathrm{K}^{\star} \mathrm{m}^{\wedge} 2 /\left(\mathrm{kg}^{\star} \mathrm{s}\right)\right]$ Date: 26.01.2003 12:00:00 Level: 440K

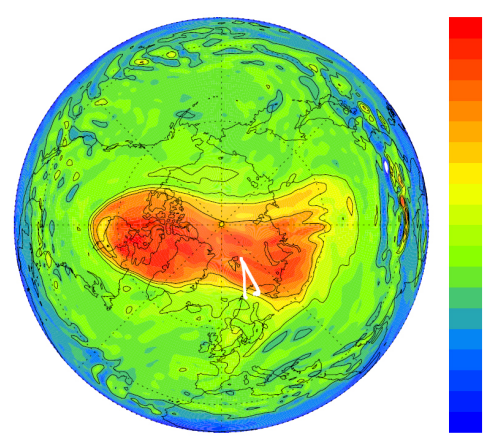

Modified PV $\left[10^{\wedge}(-6)^{\star} \mathrm{K}^{*} \mathrm{~m}^{\wedge} 2 /\left(\mathrm{kg}^{*} \mathrm{~s}\right)\right]$

Date: 21.01.2003 12:00:00 Level: 440K

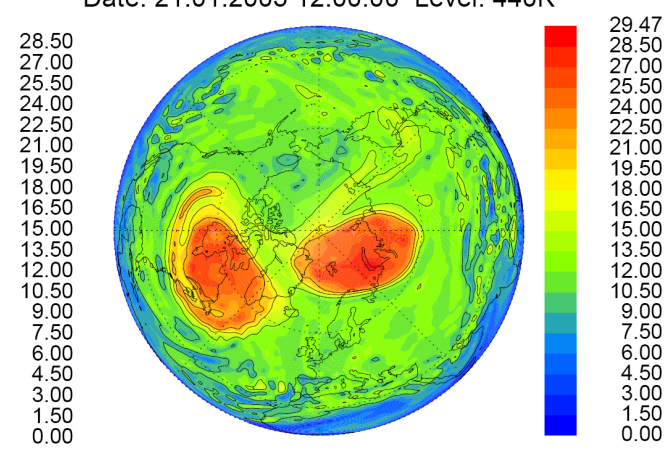

Modified PV $\left[10^{\wedge}(-6)^{\star} \mathrm{K}^{\star} \mathrm{m}^{\wedge} 2 /\left(\mathrm{kg}^{\star} \mathrm{s}\right)\right]$

Date: 23.01.2003 12:00:00 Level: 440K
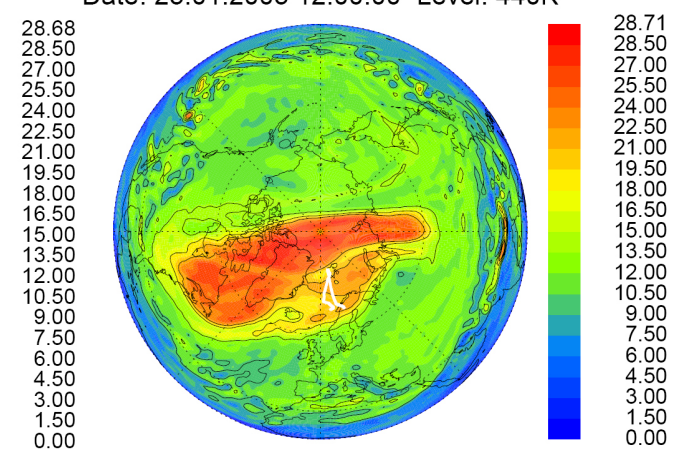

Modified PV $\left[10^{\wedge}(-6)^{\star} \mathrm{K}^{*} \mathrm{~m}^{\wedge} 2 /\left(\mathrm{kg}^{*} \mathrm{~s}\right)\right]$
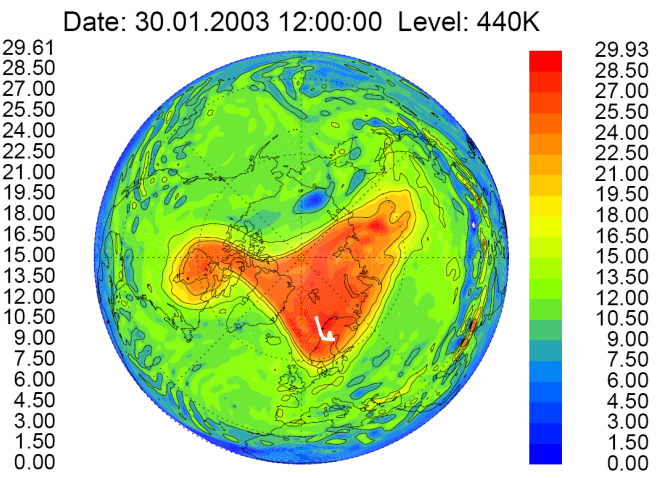

Fig. 4. Horizontal distribution of modified PV on the $440 \mathrm{~K}$ isentropic surface for 19th January (upper left), 21st (upper right), 22nd (centre left), 23rd (centre right), 26th (lower left), and 30th (lower right), 2003 (derived from ECMWF data). Contour lines are displayed at 10., 14., 18., 21. PVU. White lines correspond to flight paths of that day.

Consistently, the $\mathrm{CH}_{4}$ observations show slightly increasing values. However, as for the beginning of the flight, the observations suggest the Geophysica approaching a filament of chlorine activated air, which is not consistent with the comparably low $\mathrm{mPV}$ values in the meteorological data and the relatively high $(\approx 1.2-1.3 \mathrm{ppmv}) \mathrm{CH}_{4}$ mixing ratios.

The observations on the flight on the 26th of January are shown in Fig. 8. Most parts of the flight were carried out in vortex core air masses (see top panel of Fig. 8). Apart from some small scale features the observed values of $\mathrm{CH}_{4}$ are in agreement with the modified PV calculated from the ECMWF data. The slow decrease in $\mathrm{mPV}$ with increasing flight altitude around 12:00 indicates an approach to the vortex edge, which is however not apparent in the $\mathrm{CH}_{4}$ observations.

The increase of $\mathrm{ClO}$ at the same time is again a combined effect of the vertical gradient of total inorganic chlorine $\mathrm{Cl}_{\mathrm{y}}$ and the decrease of the solar zenith angle (not shown here) along the flight path enhancing the conversion of $\mathrm{Cl}_{2} \mathrm{O}_{2}$ into $\mathrm{ClO}$. 


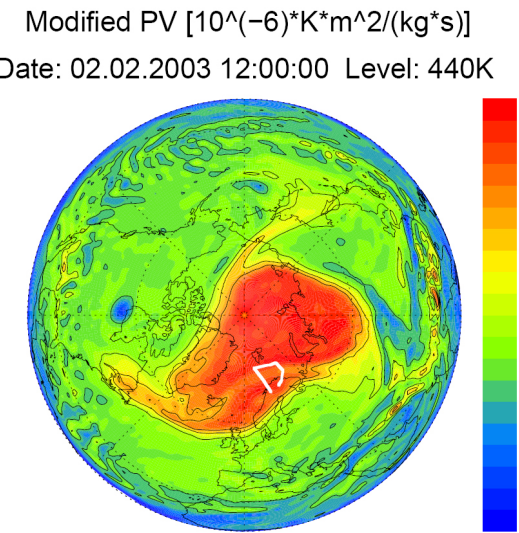

Modified PV $\left[10^{\wedge}(-6)^{\star} \mathrm{K}^{\star} \mathrm{m}^{\wedge} 2 /\left(\mathrm{kg}^{*} \mathrm{~s}\right)\right]$

Date: 15.02.2003 12:00:00 Level: 440K

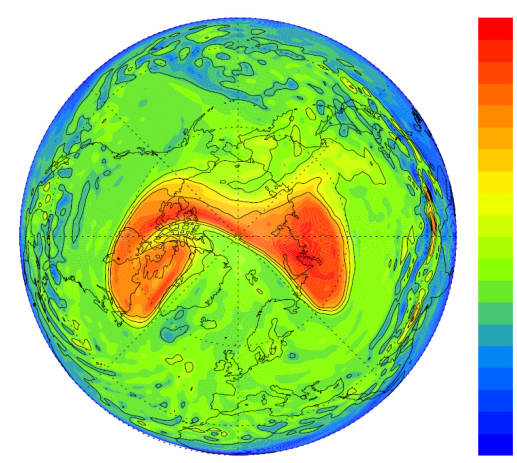

Modified PV $\left[10^{\wedge}(-6)^{\star} \mathrm{K}^{*} \mathrm{~m}^{\wedge} 2 /\left(\mathrm{kg}^{*} \mathrm{~s}\right)\right]$

Date: 23.02.2003 12:00:00 Level: 440K

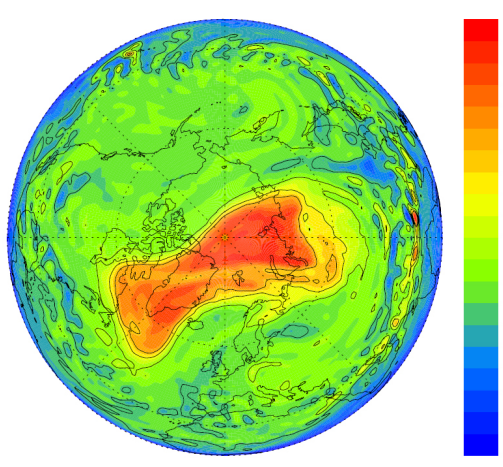

Modified PV $\left[10^{\wedge}(-6)^{\star} \mathrm{K}^{\star} \mathrm{m}^{\wedge} 2 /\left(\mathrm{kg}^{*} \mathrm{~s}\right)\right]$

Date: 11.02.2003 12:00:00 Level: 440K

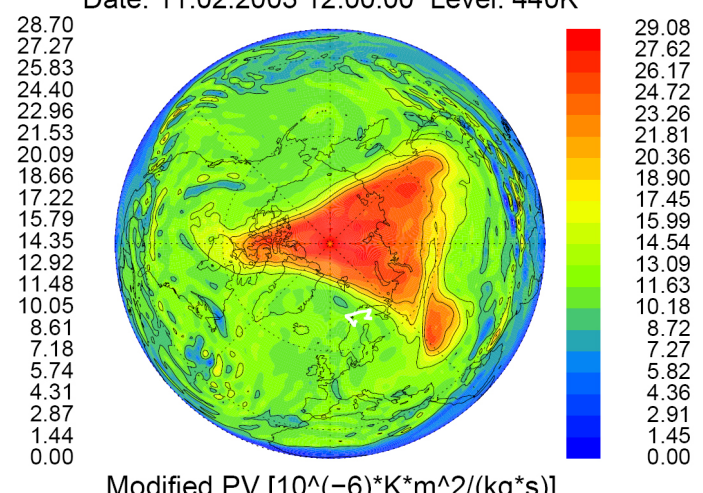

Modified PV $\left[10^{\wedge}(-6)^{*} \mathrm{~K}^{*} \mathrm{~m}^{\wedge} 2 /\left(\mathrm{kg}^{*} \mathrm{~s}\right)\right]$

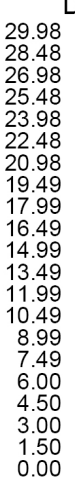

Date: 19.02.2003 12:00:00 Level: $440 \mathrm{~K}$
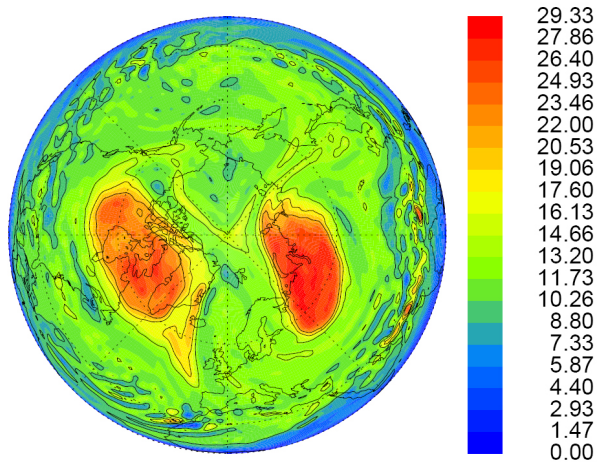

Modified PV $\left[10^{\wedge}(-6)^{*} \mathrm{~K}^{\star} \mathrm{m}^{\wedge} 2 /\left(\mathrm{kg}^{*} \mathrm{~s}\right)\right]$

Date: 28.02.2003 12:00:00 Level: 440K
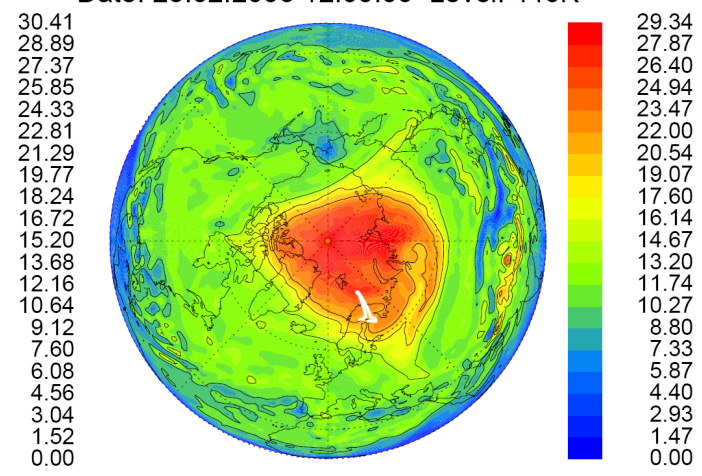

Fig. 5. Horizontal distribution of modified PV on the $440 \mathrm{~K}$ isentropic surface for 2nd February (upper left), 11th (upper right), 15th (centre left), 19th (centre right), 23rd (lower left), and 28th (lower right), 2003 (derived from ECMWF data). Contour lines are displayed at 10., 14., 18., 21. PVU. White lines correspond to flight paths of that day.

Around 12:15 the Geophysica encounters a filament of chlorine deactivated air with still very low $\mathrm{CH}_{4}$, again a feature which can not be seen in the meteorological data. After having left the vortex air masses (12:40) a very thin filament with a short dip in the $\mathrm{CH}_{4}$ values and an indication of weak chlorine activation is observed.

At the end of January strong wave activity led to a deformation of the vortex with a wave number three characteristic. During this episode, on the 2nd of February, a flight was performed when the polar vortex was located over Kiruna.
The observations obtained on this day regarding the tracer $\mathrm{CH}_{4}$ and $\mathrm{ClO}$ are shown in Fig. 9. Although the horizontal position of the vortex was perfect for a flight inside the vortex core, the Geophysica only reached the base of the vortex core during the first flight leg on $420 \mathrm{~K}$. Between 09:30 and 10:15 UT pronounced filaments of air from the vortex core and the vortex edge are encountered. Later during the second part of the flight the Geophysica was able to penetrate deeper into the vortex core, where another filament with air of significantly higher tracer values and lower $\mathrm{ClO}$ mixing ratios was 


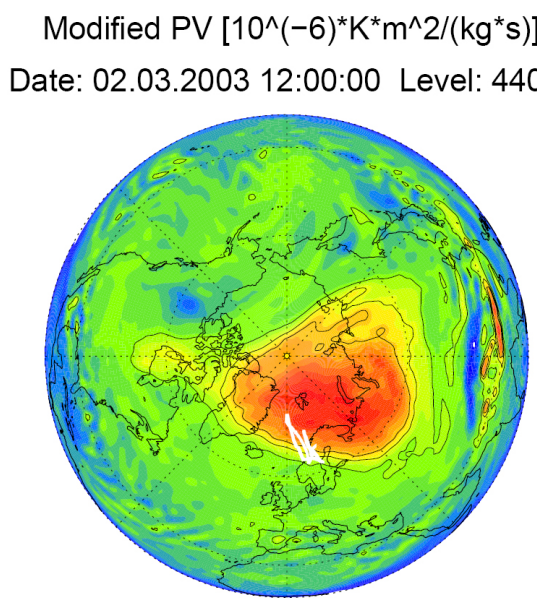

Modified PV $\left[10^{\wedge}(-6)^{*} \mathrm{~K}^{*} \mathrm{~m}^{\wedge} 2 /\left(\mathrm{kg}^{*} \mathrm{~s}\right)\right]$

Date: 12.03.2003 12:00:00 Level: 440K

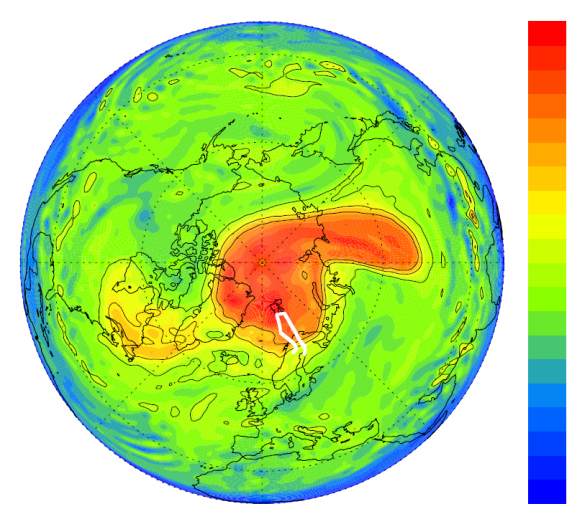

Modified PV [10^(-6)* $\left.\mathrm{K}^{\star} \mathrm{m}^{\wedge} 2 /\left(\mathrm{kg}^{*} \mathrm{~s}\right)\right]$

Date: 08.03.2003 12:00:00 Level: 440K

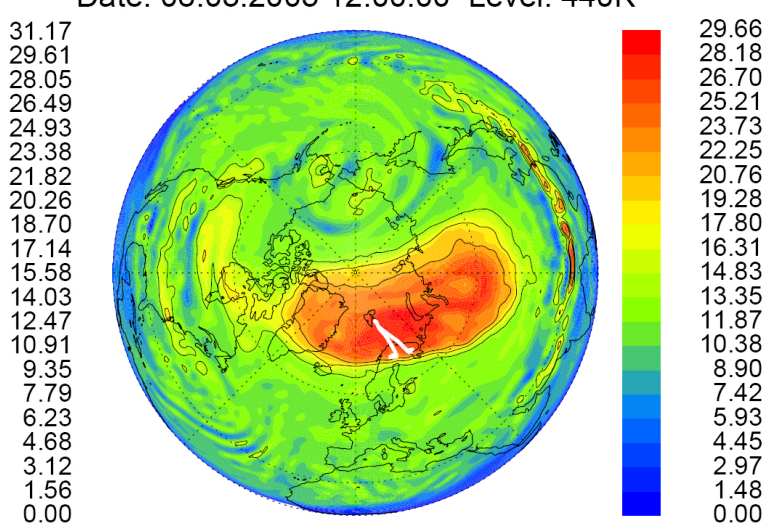

Modified PV $\left[10^{\wedge}(-6)^{*} \mathrm{~K}^{*} \mathrm{~m}^{\wedge} 2 /\left(\mathrm{kg}^{*} \mathrm{~s}\right)\right]$

Date: 16.03.2003 12:00:00 Level: 440K

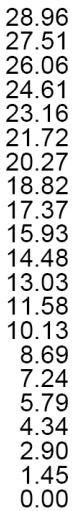

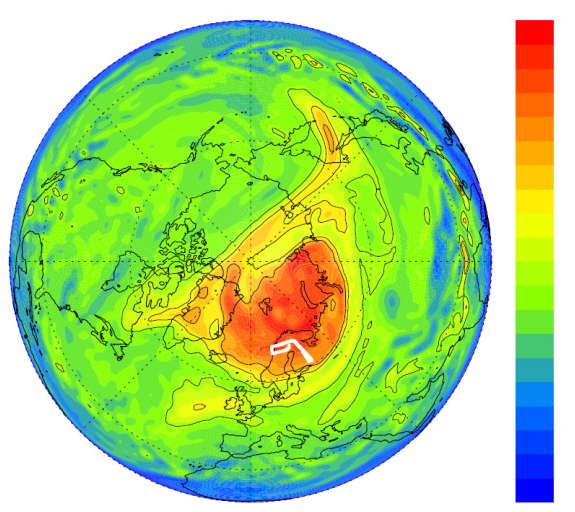

29.90

28.40

25.41

23.92

20.93

19.93

19.43
17.94

17.94
16.44

14.95

13.45

11.96

10.46

8.97

5.98

4.48

2.99

0.00

Fig. 6. Horizontal distribution of modified PV on the $440 \mathrm{~K}$ isentropic surface for 2nd March (upper left), 8th (upper right), 12th (lower left), 16th (lower right), 2003 (derived from ECMWF data). Contour lines are displayed at 10., 14., 18., 21. PVU. White lines correspond to flight paths of that day.

encountered. This filament seemed to consist at least partly of air from the vortex edge. The distribution of $\mathrm{mPV}$ on the $440 \mathrm{~K}$ isentropic level displayed in Fig. 5 suggests that the filaments encountered during this flight were part of a larger structure several hundred kilometers long. This and other occurences of filaments will be investigated in the next section.

In the framework of the ENVISAT validation campaign five flights were performed during the late stage of the decaying vortex. The observations obtained on the flight on 28th February are shown in Fig. 10. Most of the flight was clearly inside the polar vortex core with $\mathrm{CH}_{4}$ values dropping down to $1000 \mathrm{ppbv}$, at the highest flight levels even lower. Moderate chlorine activation can be observed at all times inside the vortex, with $\mathrm{ClO}$ values between $100 \mathrm{pptv}$ and more than 400 pptv. While $\mathrm{CH}_{4}$ values inside the vortex core (defined by the 21 PVU contour) are low in general, strong variablity can be observed in these areas.

\section{Simulations with CLaMS}

The most interesting dynamical features of the Arctic winter 2002/2003 besides the minor warming in December were two splits of the vortex in the lower stratosphere, which were accompanied by several large-scale roll-ups of air masses stripped from the vortex edge. Re-merging zones were formed on several occasions between secondary vortices or between the main vortex and large cut-offs merging back, thus creating filamentary structures inside the vortex core. Simultaneously filaments of vortex air were peeled off the vortex edge and moved into the mid-latitudes. The latter processes have been observed far more often than the creation of filaments by re-merging of parts of a split vortex. All of these features have in common, that their horizontal extension in one direction may be of several hundreds of kilometers, while the scale in the other direction with distances of clearly below hundred kilometres is in the order of the horizontal resolution of the ECMWF grid used. Therefore 


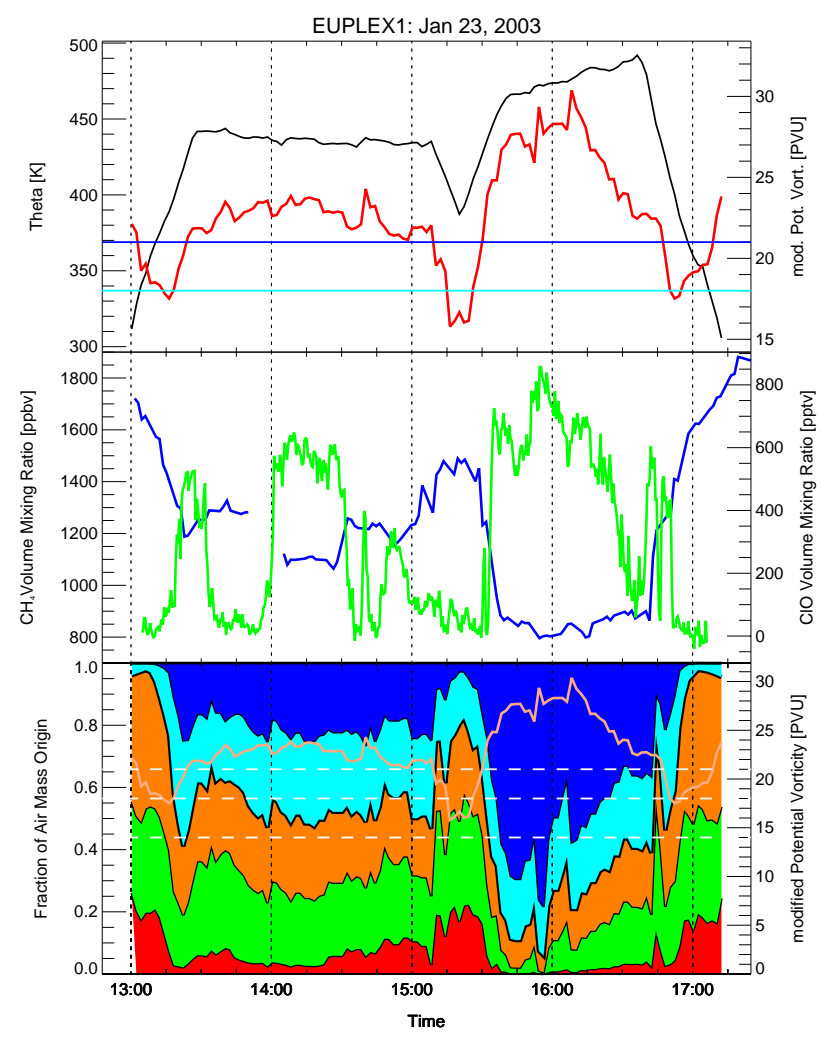

Fig. 7. Modified PV (red) and Theta (black) along the flight path (top panel) and observations of $\mathrm{CH}_{4}$ (blue) and $\mathrm{ClO}$ (green) obtained by the HAGAR instrument on-board the Geophysica on the flight from the 23rd of January, 2003 (centre panel). The bottom panel shows the mean composition of P-tracers along the flight path, displaying P0 (Tropics) in red, P1 (Mid Latitudes) in green, P2 (Outer Vortex Edge) in orange, P3 (Inner Vortex Edge) in cyan and $\mathrm{P} 4$ (Vortex Core) in blue.

they can hardly be seen in horizontal PV distributions based on these data like in Figs. 4 and 5. In the following some of these observed features will be investigated with CLaMS. The analyses presented here are all based on the simulation described in Sect. 2.

\subsection{The Re-Merging vortex: influence of extra-vortex air}

Since the CLaMS simulation was carried out with a horizontal resolution of about $70 \mathrm{~km}$, the re-merging zone, stretching from northern Siberia across Spitsbergen and central Greenland to northern Canada, can be observed much better than in ECMWF data. The results of the simulation for the $23 \mathrm{rd}$ of January for the inert P-tracers again on the $440 \mathrm{~K}$ isentropic surface are shown in Fig. 11. The distributions of the tracers P4 and P3, originally initialised in the vortex core and the inner vortex edge respectively (see Table 1), show that the strong mixing inside the vortex has led to an almost homogeneous distribution within the 7 weeks simulated. Only some islands of rather pure vortex core air have survived. Small

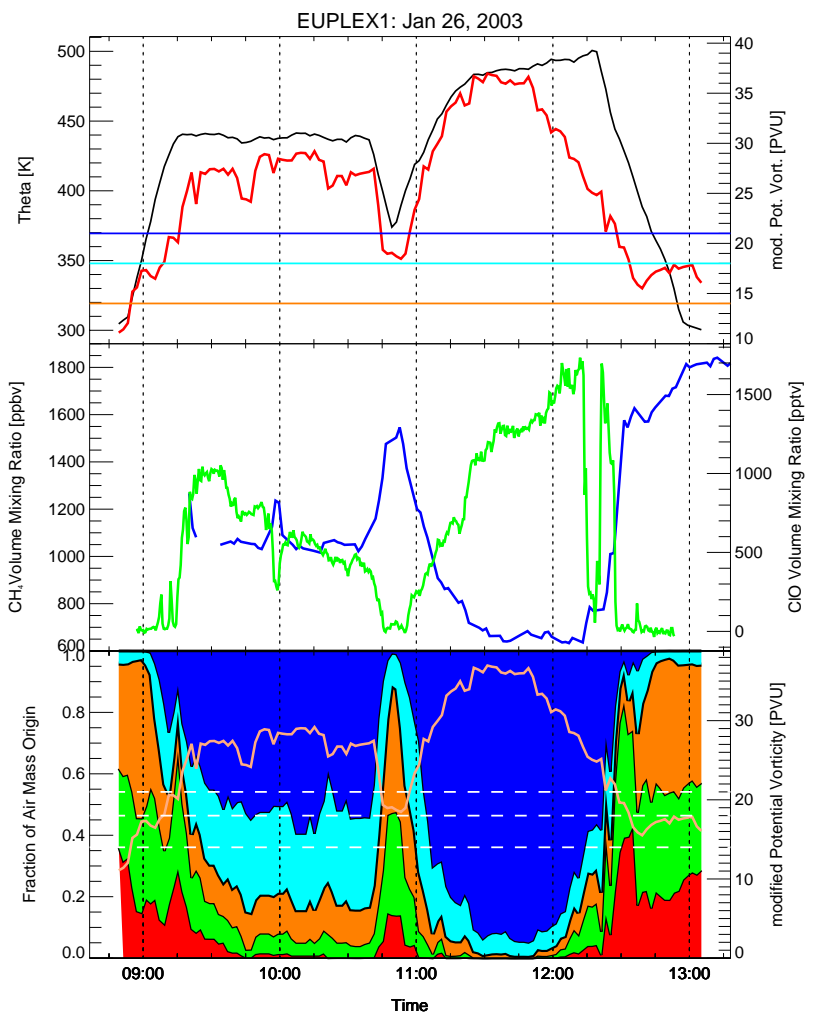

Fig. 8. Modified PV (red) and Theta (black) along the flight path (top panel) and observations of $\mathrm{CH}_{4}$ (blue) and $\mathrm{ClO}$ (green) obtained by the HAGAR instrument on-board the Geophysica on the flight from the 26th of January, 2003 (centre panel). The bottom panel shows the mean composition of P-tracers along the flight path, displaying P0 (Tropics) in red, P1 (Mid Latitudes) in green, P2 (Outer Vortex Edge) in orange, P3 (Inner Vortex Edge) in cyan and $\mathrm{P} 4$ (Vortex Core) in blue.

traces of air from the outer vortex edge (Tracer P2) can be detected inside the vortex, while no air masses from the mid latitudes and tropics have entered the vortex.

Overall $66 \%$ of the air north of $70^{\circ} \mathrm{N}$ equivalent latitude in the layer between $430 \mathrm{~K}$ and $450 \mathrm{~K}$ is still vortex air. Air masses peeled off the vortex edge and wrapped around the vortex while being transported equatorwards with substantial amounts of vortex air (more than $40 \%$ of tracer P4 and P3 within some filaments) can be identified too. These filaments make up as much as $6 \%$ of the mid-latitude air outside the vortex in a $20 \mathrm{~K}$ thick layer centred on $440 \mathrm{~K}$.

The re-merging zone is clearly visible in the distribution of all tracers. It is almost completely free of vortex core air, with contributions of mainly air from the inner and outer vortex edge (P2) and the mid latitudes (P1). Even some influence of air originating in the tropics (P0) can be observed. In the central area of the re-merging zone over Greenland substantial influence of vortex air is noticeable, while mid latitudinal and tropical air dominate its eastern and western 


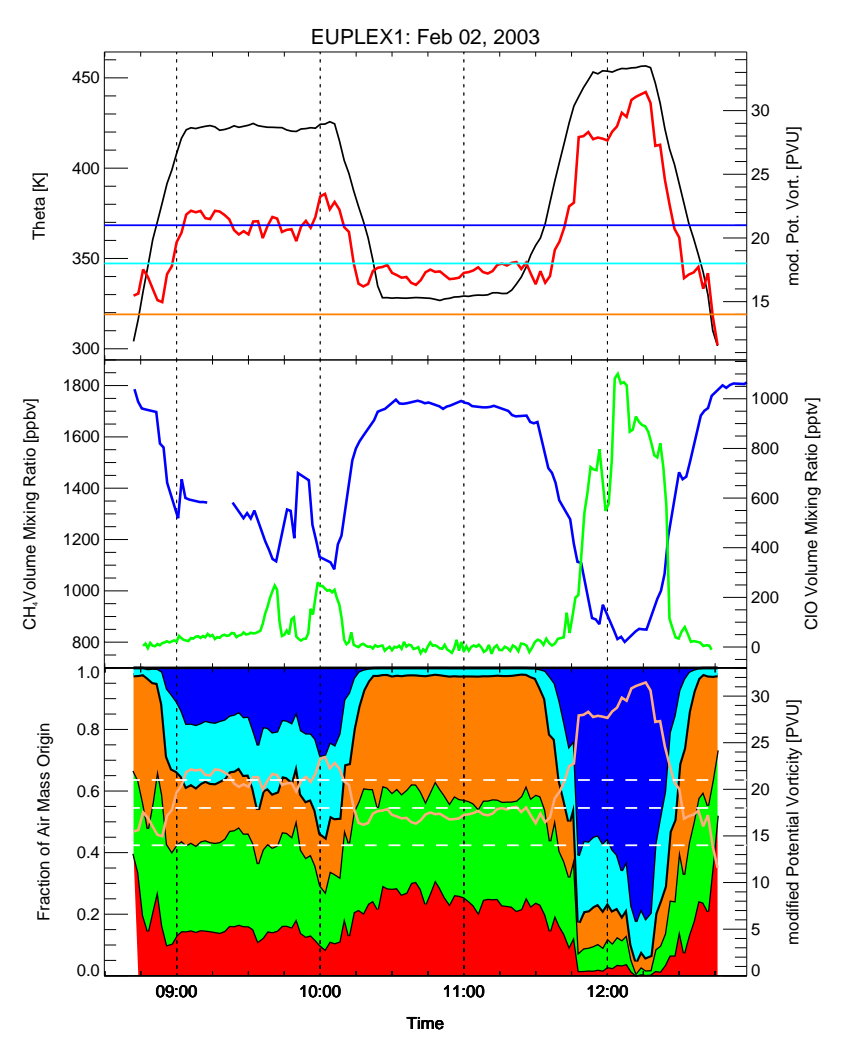

Fig. 9. Modified PV (red) and Theta (black) along the flight path (top panel) and observations of $\mathrm{CH}_{4}$ (blue) and $\mathrm{ClO}$ (green) obtained by the HAGAR instrument on-board the Geophysica on the flight from the 2nd of February 2003 (centre panel). The bottom panel shows the mean composition of P-tracers along the flight path, displaying P0 (Tropics) in red, P1 (Mid Latitudes) in green, P2 (Outer Vortex Edge) in orange, P3 (Inner Vortex Edge) in cyan and $\mathrm{P} 4$ (Vortex Core) in blue.

part over Siberia and Canada, respectively. This is because in this central area of the re-merging zone the two lobes came closest and started to re-connect, thus showing the strongest horizontal wind shear, which in turn enhances the mixing intensity.

In general the model results indicate that the splitting of the polar vortex led to enhanced transport of lower latitude air into the area covered by the secondary vortices due to a weakening of the transport barrier maintained by the vortex boundary. Furthermore this event led to strong intra-vortex mixing between air originating from the vortex core and the inner vortex edge. The re-merging of the secondary vortices again increased the amount of extra-vortex influence inside the vortex by engulfing the filament of lower latitudinal air that has formed during the vortex split.

\subsection{The re-merging vortex: flights in January}

On several days during this unusual dynamical situation Geophysica flights were carried out, thus giving the opportunity

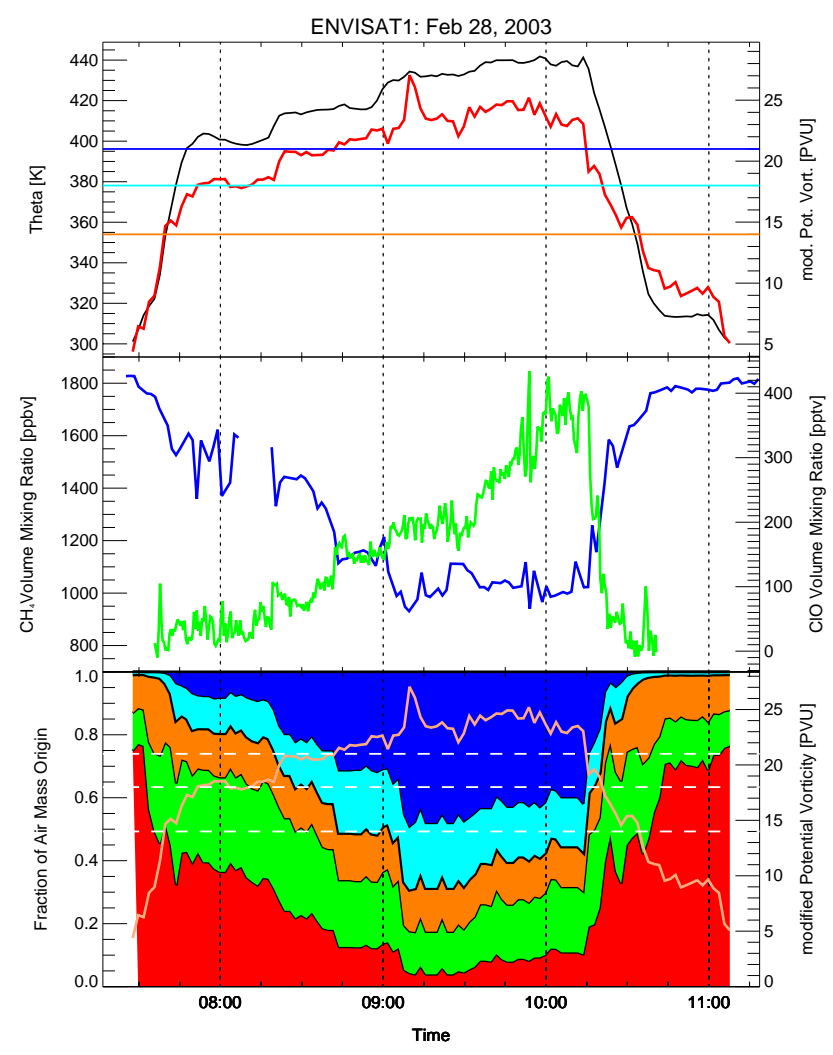

Fig. 10. Modified PV (red) and Theta (black) along the flight path (top panel) and observations of $\mathrm{CH}_{4}$ (blue) and $\mathrm{ClO}$ (green) obtained by the HAGAR instrument on-board the Geophysica on the flight from the 28th of February, 2003 (centre panel). The bottom panel shows the mean composition of P-tracers along the flight path, displaying P0 (Tropics) in red, P1 (Mid Latitudes) in green, P2 (Outer Vortex Edge) in orange, P3 (Inner Vortex Edge) in cyan and $\mathrm{P} 4$ (Vortex Core) in blue.

to study some dynamical features of the lower part of the polar vortex more closely.

The centre panel of Fig. 7 shows observations of $\mathrm{CH}_{4}$ made on-board the Geophysica on the 23rd of January 2003. The bottom panel of Fig. 7 displays the P-tracer composition of the air masses simulated by CLaMS along the flight path, indicating the influence of different air mass origins in the areas probed. Displayed are mean values derived from CLaMS air masses located in a corridor along the flight path with a maximum distance of $40 \mathrm{~km}$ in the horizontal and $3 \mathrm{~K}$ in the vertical direction advected to the nearest synoptic point in time, where CLaMS output exists (in this case 12:00 on the 23rd of January).

The flight on this day was aimed at probing the re-merging zone. As for all the other flights for the EUPLEX and ENVISAT validation campaign, the Geophysica only reached the lowest parts of the polar vortex. These can easily be identified by the areas, where $\mathrm{CH}_{4}$ (centre panel) shows low values, indicating air transported downward by diabatic descent inside the vortex from the middle stratosphere, where the abundances of these tracers are generally lower. 


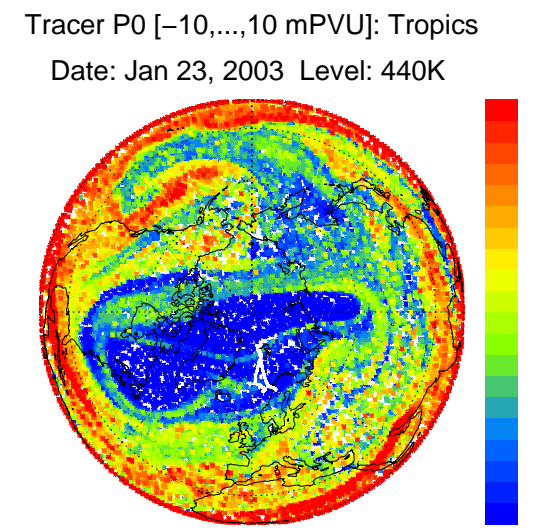

Tracer P2 [14,.., $18 \mathrm{mPVU}]$ : Outer Vortex Edge

Date: Jan 23, 2003 Level: 440K

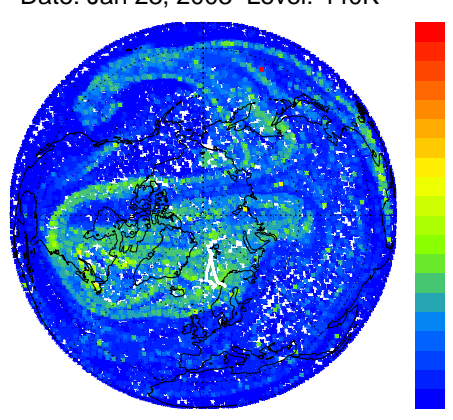

Tracer P1 $[10, \ldots, 14 \mathrm{mPVU}]:$ Mid-Latitudes

Date: Jan 23, 2003 Level: 440K

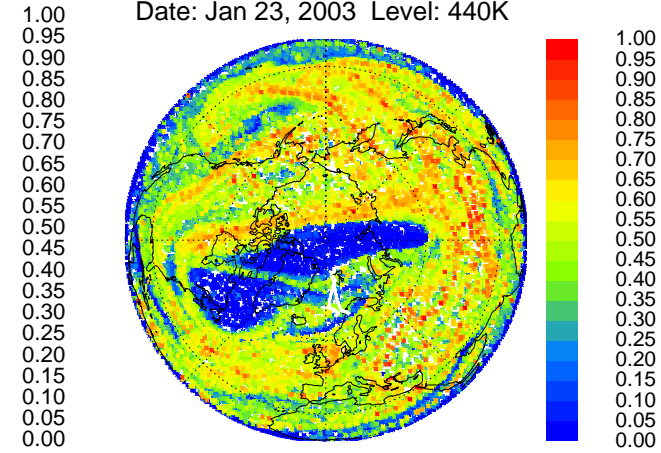

Tracer P3 [18,..,21 mPVU]: Inner Vortex Edge

Date: Jan 23, 2003 Level: 440K

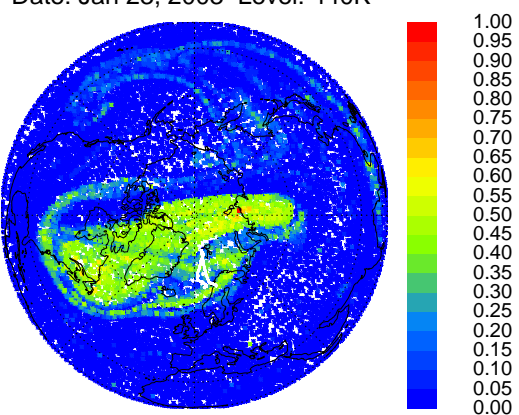

Tracer P4 [> $21 \mathrm{mPVU}]$ : Vortex Core

Date: Jan 23, 2003 Level: 440K

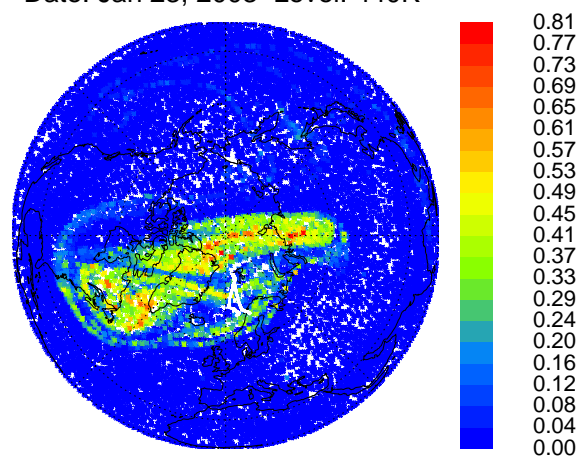

Fig. 11. Horizontal distribution of the inert tracers $\mathrm{P} 0$ to $\mathrm{P} 4$ (see text) on the $440 \mathrm{~K}$ isentropic surface taken from CLaMS results. For the corresponding modified PV distribution derived from ECMWF data see Fig. 4 (centre right).

On this flight, the Geophysica encountered air from inside the vortex, i.e. the vortex core and the inner vortex edge, already during ascent and shortly after having reached the $440 \mathrm{~K}$ level. This is in good agreement with the CLaMS results, while the next encounter with vortex air around 14:00 seems to be shifted to earlier times in the model results and is not as apparent as in the observations. The $\mathrm{mPV}$ derived from ECMWF data shows no indication of vortex air during the first $\mathrm{ClO}$ peak. The following encounters with air masses showing low $\mathrm{CH}_{4}$ values are again in good temporal alignment with the distribution of P-tracers. The same holds true for the increase of outer vortex influences around 16:00 as well as for the filament of chlorine activated air and its finescale structure encountered during the final descent.

The influence from air originating from the vortex core and the inner vortex edge simulated by CLaMS in a vertical cross-section along the flight path is displayed in Fig. 12. After summing up the amount of tracers P4 (vortex core) and P3 (inner vortex edge) in every air parcel in a curtain with a maximum horizontal distance of $60 \mathrm{~km}$ from the flight path, thus creating a measure for the vortex influence. These values are binned in $60 \mathrm{~s}$ flight time and $10 \mathrm{~K}$ vertical range. The 
EUPLEX : Influence from Vortex Core and Inner Edge Date: Jan 23, 2003

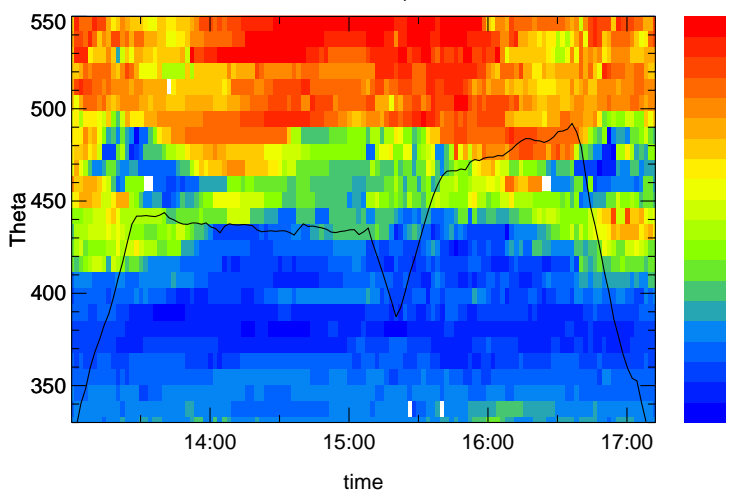

1.00
0.95
0.90
0.85
0.80
0.75
0.70
0.65
0.60
0.55
0.50
0.45
0.40
0.35
0.30
0.25
0.20
0.15
0.10
0.05
0.00

Fig. 12. Vortex influence derived from the sum of the tracers $P 4$ and P3 along the flight path for the flight on the 23rd of January, 2003, averaged in bins of $60 \mathrm{~s}$ and $10 \mathrm{~K}$. White areas denote bins with no CLaMS air parcels.

filament of vortex influenced air encountered during ascent and descent, which is very prominent in the observations of $\mathrm{ClO}$, has a vertical extent of about $50 \mathrm{~K}$ and consists of up to $80 \%$ vortex air. This feature can not be seen in the $\mathrm{mPV}$ distribution derived from ECMWF data.

In general, there is good agreement between observation and simulation regarding temporal alignment and vortex influence. Exceptions may be due to the fact, that (i) the CLaMS results shown in the lower panel of Fig. 7 are derived from an interpolation onto the flight path by the averaging processes described, and that (ii) the observations are at a comparatively higher resolution, vertically and horizontally, than the CLaMS simulation. Nevertheless, the strong filamentation observed can be reproduced by the model. The amount of original vortex air inside the vortex has decreased from $66 \%$ on 19th January to $51 \%$ in the $440 \mathrm{~K}$ layer, showing that strong mixing has been going on during the previous four days. These values are calculated by integrating the tracer distributions of P3 (inner vortex edge) and P4 (vortex core) inside the $18 \mathrm{mPV}$ units contour line (see Fig. 11).

The CLaMS results for the next flight on the 26th of January (see Fig. 8, bottom panel) show in general good agreement with the observations and the PV calculated from the ECMWF analyses. The tiny filaments of chlorine activated air from the vortex encountered during ascent shortly before arriving at the first cruise level are represented as a broader feature of increased influence of vortex air in the CLaMS results. The small filament with higher amount of extra vortex air observed around 10:00 is not as sharp in the model results as in the observations. The increase of extra vortex air later on the second flight leg (shortly after 12:00) and the small filament of vortex air met shortly afterwards agree very well with the observations. Even the very fine filament of chlorine activated air encountered during descent is represented in the

\section{EUPLEX : Influence from Vortex Core and Inner Edge} Date: Jan 26, 2003

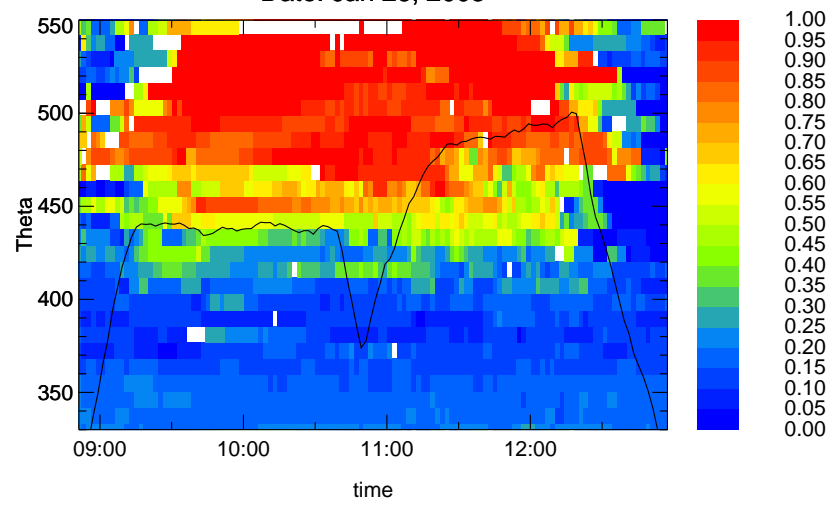

Fig. 13. Vortex influence derived from the sum of the tracers $P 4$ and P3 along the flight path for the flight on the 26th of January 2003, averaged in bins of $60 \mathrm{~s}$ and $10 \mathrm{~K}$. White areas denote bins with no CLaMS air parcels.

model results as a sharp increase in influence from vortex air.

The averaged distribution of the tracers tagging air from the vortex core and the inner vortex edge in a curtain along the flight track displayed in Fig. 13 again gives a better overview about the vertical structure of the simulated vortex. The base of the vortex is characterized by both, erosion and filamentation. The small filaments encountered during ascent and descent (both visible in the observations, but not in the $\mathrm{mPV}$ derived from the meteorological data) are prominent in the model results. There are additional shallow structures of air dominated by vortex influence only apparent rudimentally in the observations. Although their vertical extent is only about $10 \mathrm{~K}$, they consist of 40 to $50 \%$ air originally located inside the vortex boundary.

The filamentary structure generated mainly by the vortex split can be seen in both, the observations and the results of the model simulation. Although the model lacks the fine resolution of the observations the agreement between the features observed and those simulated is good. The erosion of the vortex base is accompanied by shallow filaments of inner vortex air characterized by significant chlorine activation.

\subsection{The disturbed vortex in early February}

During the flight on 2nd February (see Fig. 9) it was possible to meet an aged filament created during a vortex re-merging process twice (around 09:30 and 12:00). The history of the filament can be tracked back for about 4 days. The eastern part of the filament, which is probed first, is located more to the edge of the vortex, while the western part is already drawn more into the re-merging vortex. Especially the second encounter with the old filament is clearly visible in both model results and observations. During the first part of the flight, the encounter is smeared out in the model results and 
also not visible in the $\mathrm{ClO}$ measurements. This may be due to the fact that the first part of the flight was on a lower level and in an area where the erosion of the vortex and the filaments seems to be stronger, while the second part of the flight took place $30 \mathrm{~K}$ higher up and deeper inside the newly reunited vortex. According to CLaMS results, the vortex at the $440 \mathrm{~K}$ layer at this time consisted of about $60 \%$ air of original vortex origin, meaning that its interior had been filled up with vortex core air moving downward due to radiative cooling.

\subsection{The aged vortex at the end of February}

The CLaMS results for the flight on the 28th of February into an already aged vortex are shown in the bottom panel of Fig. 10. The slow ascent into the lower part of the vortex indicated by the slow decrease in the observed $\mathrm{CH}_{4}$ is in good agreement with the increase in vortex influence in the model results along the flight path. The observed filamentation is not reflected in the composition of the air parcels inside the lower part of the vortex as simulated by CLaMS, which show only a small variability. The vortex edge encountered by the Geophysica while descending is well reproduced by the model. Small filaments observed afterwards in the vicinity of the vortex edge are matched by the model quite well.

Both, observations and model results show that the interior of the polar vortex underwent intense mixing during the vortex split in mid January and the following re-merge. Air masses from the vortex core and the inner edge were strongly mixed, and enhanced transport from lower latitudes resulted in strong influence from the outer edge and the mid-latitudes. Small scale and shallow filaments were formed inside the vortex and in the vicinity of the edge. The model simulation shows vortex air being peeled off the vortex air and moved to mid-latitudes. An estimate of the influence of outer vortex air on the vortex and vice versa is given in the next subsection.

\subsection{The influence of transport across the vortex edge}

Another interesting aspect that can be investigated with the help of origin spectra is shown in Fig. 14. Displayed is the temporal evolution of the average composition of the vortex (i.e. all air masses with $\mathrm{mPV} \geq 18$ ) in the altitude range between 400 and $850 \mathrm{~K}$. After a short spin-up of the model during the first days, the mixing induced by the strong perturbations of the vortex during the minor warming in December led to a constant increase of extra vortex air masses inside the vortex to about $21 \%$. Between the end of December and mid January the increasing stability of the vortex led to stronger PV gradients at the vortex boundary, resulting in very limited transport across the vortex edge. Only during the strongest wave breaking events in mid January and mid February an increase in extra-vortex air inside the vortex to values of more than $30 \%$ can be observed, indicating the strong impact of the re-merging events on the vortex composition. The amount

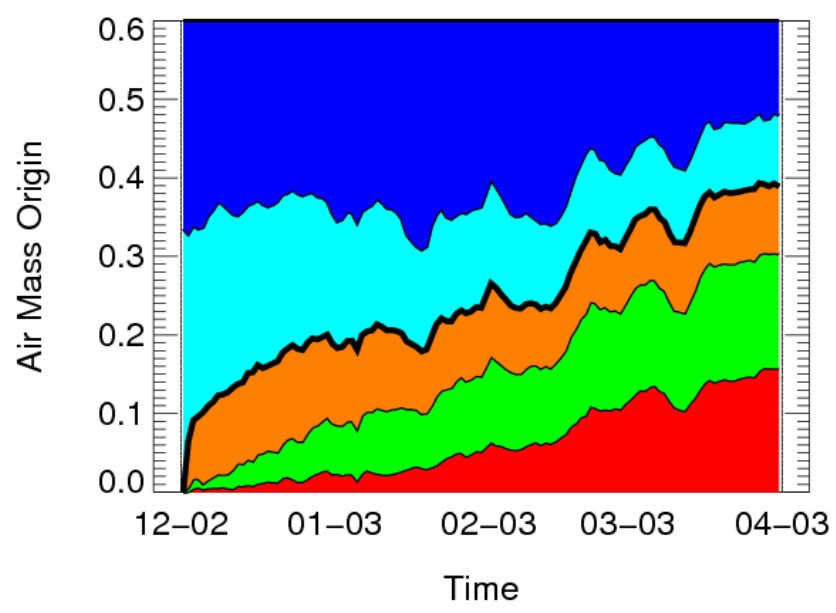

Fig. 14. Temporal evolution of the vortex composition with respect to the inert p-tracers for the lower and middle stratosphere $(400 \mathrm{~K}-$ $850 \mathrm{~K})$.

of air coming originally from areas with $\mathrm{mPV}$ values below 10 PVU (i.e. the tropics) increases up to $11 \%$ until the end of February. After the wave breaking events (end of December to mid January and the first half of February) the downward motion inside the vortex leads to an increase of vortex tracers and decrease of extra-vortex influence. After mid February, when the vortex splits for the second time, and in March, when the final warming and the vortex breakdown is about to start, influence from the outer vortex edge, the mid-latitudes and subtropics is increasing to values of about $32 \%$.

In Fig. 15 the zonal mean based on equivalent latitudes of the simulated air mass origin for lower stratospheric air between $400 \mathrm{~K}$ and $850 \mathrm{~K}$ is shown. The air mass origin is initialized on the 1st of December 2002 according to Fig. 1. On the 19th of January 2003 (top panel), after about six weeks of simulation and right before the first vortex split, the air in the polar vortex remains largely isolated from mid-latitude air. Only $18 \%$ of the air masses inside the vortex core area north of $65^{\circ} \mathrm{N}$ equivalent latitude (the location of the vortex edge) in the altitude range between $400 \mathrm{~K}$ and $850 \mathrm{~K}$ are of extravortex origin. Indeed, the gradient between air masses of different origin at the polar vortex edge is very strong as it is apparent as a very narrow range of equivalent latitudes where the air shows a mixed composition between mid-latitude and vortex air. A small fraction of vortex air $\left(\approx 4 \%\right.$ south of $65^{\circ} \mathrm{N}$ equivalent latitude) has been transported out of the vortex. Further noticeable is that tropical and mid-latitude air masses are mixed to some extent.

The situation on the 11th of February 2003 (the last flight day of the EUPLEX campaign) is remarkably similar to mid January (Fig. 15, centre panel). The gradient at the vortex edge has steepened compared to mid January. There is almost the same fraction of polar air at mid-latitudes (south of the vortex edge at $65^{\circ} \mathrm{N}$ equivalent latitude) as in mid 

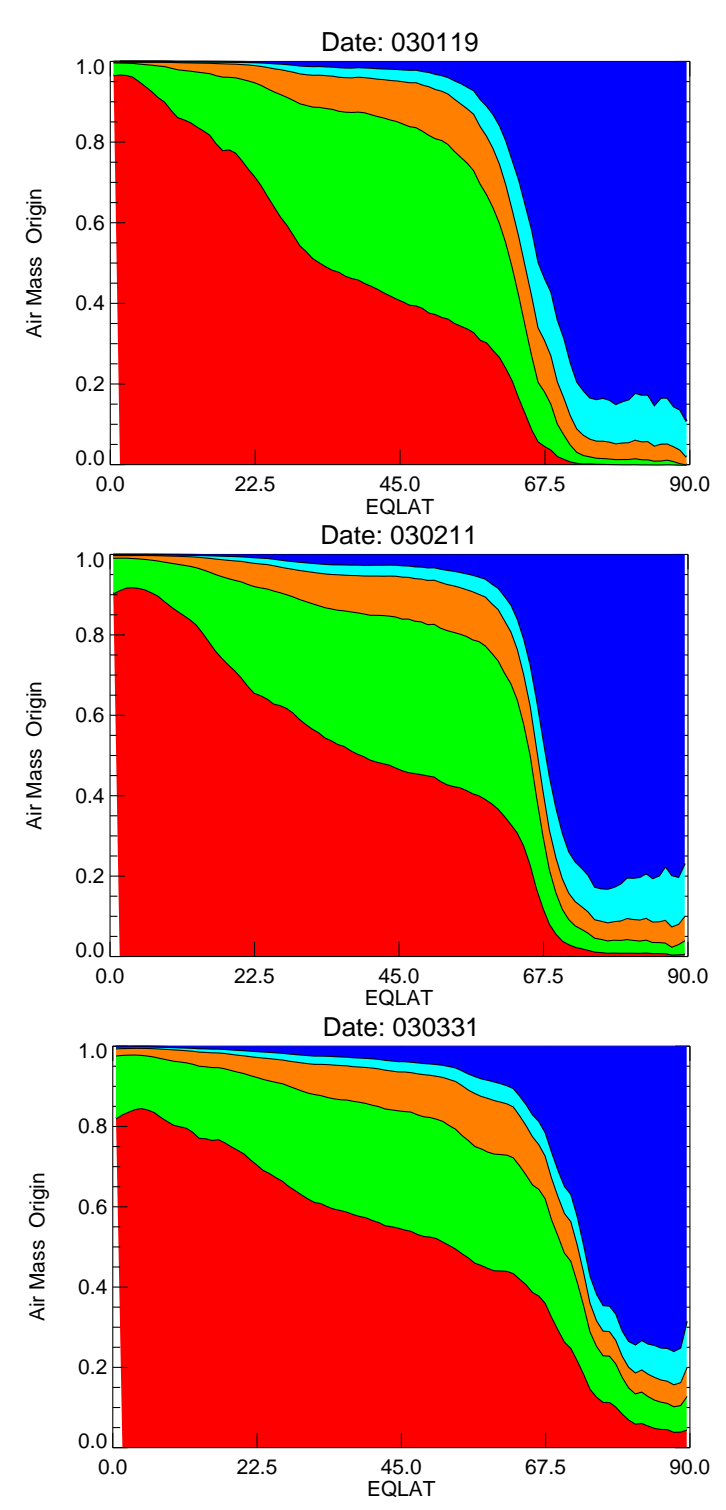

Fig. 15. Zonally averaged air mass origin in the lower stratosphere (from $400-850 \mathrm{~K}$ potential temperature) versus equivalent latitude for 19 January (top), 22 February (centre) and 31 March (bottom).

January and there is a slighly lower fraction of pure vortex core air within the vortex (68\%) that now also contains about $22 \%$ of air masses of extra vortex air, some even of tropical origin $(6 \%)$.

Even by the end of March (see Fig. 15, bottom panel) the transport barrier at the edge of the vortex (now located at $70^{\circ} \mathrm{N}$ equivalent latitude) is clearly noticeable and the vortex contains about $60 \%$ pure vortex air (indicated by the blue colour). Transport of vortex air to mid-latitudes has increased compared to the situation in January and February $(\approx 5 \%)$. The influence of vortex air is strongest at high equivalent latitudes, that is close to the polar vortex, and decreases equatorwards.
For a precise estimate of the impact of the transport of polar air out of the vortex on mid-latitude ozone, simulations including the transport and chemistry of ozone would be required. However, assuming that the air in the polar vortex at the beginning of the winter has ozone mixing ratios about as large as the mid-latitude air and assuming that ozone has been completely chemically destroyed in the polar vortex during winter, one would estimate that the mid-latitude ozone levels by the end of March would have been reduced by about 5\% due to the export of polar vortex air. In reality, ozone in the Arctic vortex is not destroyed completely, so that this value constitutes an upper limit. The estimate of $5 \%$ corresponds to the fraction of air outside the vortex, a value that represents $60 \%$ of the vortex interior at the end of March.

The results indicate that as long as a polar voxtex exists, the impact of ozone loss on mid-latitude ozone trends will be small. This impact should be even smaller in Arctic winters with a stronger vortex than in 2002/2003 or in the Antarctic.

\section{Conclusions}

The Arctic winter 2002/2003 showed an unusual dynamical situation with strong planetary wave activity leading to perturbations of the polar vortex. Two splits of the polar vortex in the lower stratosphere followed by re-merging of the separated secondary vortices a few days later resulted in enhanced formation of filaments of extra vortex air being folded into the remerging vortices. These air masses were then subsequently mixed into the interior of the newly created vortex. The same events caused air masses being peeled off from the vortex edge and being transported into the mid-latitudes, taking with them a small amount of former vortex core air.

The observations of $\mathrm{ClO}$ onboard the high-flying aircraft Geophysica obtained during the field campaign EUPLEX and an ENVISAT validation phase from mid January to mid March show a polar vortex with significant chlorine activation. Evidence for filaments was observed at the vortex edge as well as in its interior. Model results from the CLaMS model projected onto the flight paths are consistent with the observations and are helpful analysing and understanding the observed values of e.g. $\mathrm{ClO}$ and $\mathrm{CH}_{4}$.

The comparison between model results and observations shows that in general the distribution of the observed species can be analyzed and sometimes better be understood when origin spectra based on inert tracers are taken into account. The influence of different parts of the vortex, the vortex edge and mid-latitudes can be analyzed on small scales as e.g. along flight paths as well as on global scales.

Model calculations using the CLaMS model were used to investigate the spectrum of air mass origins of each individual air parcel in the model. We find that the Arctic vortex in winter 2002/2003 remained relatively isolated, excepting the time periods of the two splits and re-merging events 
of the polar vortex in the lower stratosphere. The strong perturbations during December 2002 increased the extra-vortex air masses inside the Arctic vortex to about $21 \%$, mainly because the vortex edge was weak in the beginning of the winter, when the vortex formation has not been completed. The first of the split events during January led to an additional increase of air from the outside of the vortex of about $3 \%$ for the altitude range from $400 \mathrm{~K}$ to $850 \mathrm{~K}$, with significant contributions from the mid-latidues and the tropics (tracers P0 and P1, respectively). The second more pronounced split in February increased the in-mixed mid-latitudinal air by about $8 \%$. The dynamical situation during February enhanced the transportof air from the lower latitudes poleward, leading to an higher amount of air of mid-latitudinal and tropical origin being enclosed into the re-merging vortex. During these episodes extra-vortex air entered the vortex not only by being mixed across the vortex edge, but mainly by being engulfed by the re-merging vortex, thereby forming thin filamentary structures, which afterwards mixed with the vortex background air on a timescale of several days.

During March, when the decaying Arctic vortex was disturbed by pronounced wave number one and two events, the amount of extra-vortex air increased to a total of about $38 \%$. Grooß et al. (2008) found that the impact of in-mixing events leads to lower estimates of ozone loss of about $39 \%$ in the range between $400 \mathrm{~K}$ and $450 \mathrm{~K}$ (12 DU) during the same winter.

In the mid-latitudes the air masses which have been drawn from the vortex core and edge by the above described dynamical situations are slowly mixed into the background air. Our model calculations suggest this transport from the polar vortex into the mid-latitudes to result in a fraction of the order of 5\% for the lower stratosphere until the end of March. This can serve as an estimate for the maximum impact of Arctic ozone depletion on the mid-latitudes before the break up of the polar vortex.

Knudsen and Grooß (2000) found that $40 \%$ of the midlatitude ozone depletion in May for the years 1995 and 1997 was due to dilution. Using a high resolution CTM for the cold Arctic winter 1999/2000 Marchand et al. (2003) report values of about $50 \%$ for the time period from December to April. In a study by Millard et al. (2002), where CTM simulations were used to quantify the contribution of polar vortex air to mid-latitude ozone loss for the period from December to May for the years 1994 to 2000, an interannual variability between almost 0 DU and 25 DU was found.

Based on the simulations described in Grooß et al. (2008) a maximum value for the ozone depletion in mid-latitudes until the end of March 2003 of $10 \%$ ( $\approx 25$ DU) can be derived (Grooß, private communications). This value includes both in-situ chemistry and dilution with ozone depleted vortex air. Taking into account the value of $5 \%$ for the maximum impact of dilution deduced in this study, this implies that the upper limit for ozone dilution in mid-latitudes is $50 \%$ (12 DU) for March 2003, which is in agreement with the studies of Knud- sen and Grooß (2000) and Marchand et al. (2003). Likewise a value of $12 \mathrm{DU}$ is in the range of the results presented by Millard et al. (2002).

Acknowledgements. The authors would like to thank the European Centre for Medium-Range Weather Forecasts (ECMWF) for providing the meteorological data, and N. Spelten, N. Thomas and R. Bauer for excellent support with data handling and programming.

Edited by: P. Haynes

\section{References}

Brune, W. H., Anderson, J. G., and Chan, K. R.: In-situ observations of $\mathrm{ClO}$ in the Antarctic: ER-2 aircraft results from $54^{\circ} \mathrm{S}$ to $72^{\circ} \mathrm{S}$ latitude, J. Geophys. Res., 94, 16 649-16663, 1989.

Christensen, T., Knudsen, B. M., Streibel, M., Anderson, S. B., Benesova, A., Braathen, G., Davies, J., De Backer, H., Dier, H., Dorokhov, V., Gerding, M., Gil, M., Henchoz, B., Kelder, H., Kivi, R., Kyrö, E., Litynska, Moore, D., Peters, G., Skrivankova, P., Stübi, R., Turunen, T., Vaughan, G., Viatte, P., Vik, A. F., von der Gathen, P., and Zaitcev, I.: Vortex-averaged Arctic ozone depletion in the winter 2002/2003, Atmos. Chem. Phys., 5, 131138, 2005, http://www.atmos-chem-phys.net/5/131/2005/.

Goutail, F., Pommereau, J.-P., Lefèvre, F., Roozendael, M. V., Andersen, S. B., Kåstad-Høiskar, B.-A., Dorokhov, V., Kyrö, E., Chipperfield, M. P., and Feng, W.: Early unusual ozone loss during the Arctic winter 2002/2003 compared to other winters, Atmos. Chem. Phys., 5, 665-677, 2005,

http://www.atmos-chem-phys.net/5/665/2005/.

Grooß, J.-U., Günther, G., Müller, R., Konopka, P., Bausch, S., Schlager, H., Voigt, C., Volk, C. M., and Toon, G. C.: Simulation of denitrification and ozone loss for the Arctic winter 2002/2003, Atmos. Chem. Phys., 5, 1437-1448, 2005, http://www.atmos-chem-phys.net/5/1437/2005/.

Grooß, J.-U., Müller, R., Konopka, P., Steinhorst, H.-M., Engel, A., Möbius, T., and Volk, C. M.: The impact of mixing across the polar vortex edge on Match ozone loss estimates, Atmos. Chem. Phys., 8, 565-578, 2008,

http://www.atmos-chem-phys.net/8/565/2008/.

Hadjinicolaou, P. and Pyle, J.: The impact of Arctic ozone depletion on northern middle latitudes: interannual variability and dynamical control, J. Atmos. Chem., 47, 25-43, 2004.

Knudsen, B. M. and Grooß, J. U.: Northern midlatitude stratospheric ozone dilution in spring modeled with simulated mixing, J. Geophys. Res., 105, 6885-6890, 2000.

Konopka, P., Grooß, J.-U., Bausch, S., Müller, R., McKenna, D. S., Morgenstern, O., and Orsolini, Y.: Dynamics and chemistry of vortex remnants in late Arctic spring 1997 and 2000: Simulations with the Chemical Lagrangian Model of the Stratosphere (CLaMS), Atmos. Chem. Phys., 3, 839-849, 2003, http://www.atmos-chem-phys.net/3/839/2003/.

Konopka, P., Steinhorst, H.-M., Grooß, J.-U., Günther, G., Müller, R., Elkins, J. W., Jost, H.-J., Richard, E., Schmidt, U., Toon, G., and McKenna, D. S.: Mixing and Ozone Loss in the 1999-2000 Arctic Vortex: Simulations with the 3-dimensional Chemical Lagrangian Model of the Stratosphere (CLaMS), J. Geophys. Res., 109, D02315, doi:10.1029/2003JD003792, 2004. 
Konopka, P., Günther, G., McKenna, D. S., Müller, R., Offermann, D., Spang, R., and Riese, M.: How homogeneous and isotropic is stratospheric mixing? Comparison of CRISTA-1 observations with transport studies based on the Chemical Lagrangian Model of the Stratosphere (CLaMS), Q. J. R. Meteorol. Soc., 131, 565579, doi:10.1256/qj.04.47, 2005.

Konopka, P., Günther, G., Müller, R., dos Santos, F. H. S., Schiller, C., Ravegnani, F., Ulanovsky, A., Schlager, H., Volk, C. M., Viciani, S., Pan, L. L., McKenna, D.-S., and Riese, M.: Contribution of mixing to upward transport across the tropical tropopause layer (TTL), Atmos. Chem. Phys., 7, 3285-3308, 2007, http://www.atmos-chem-phys.net/7/3285/2007/.

Lait, L. R.: An alternative form for potential vorticity, J. Atmos. Sci., 51, 1754-1759, 1994.

Mahowald, N. M., Plumb, R. A., Rasch, P. J., del Corral, J., and Sassi, F.: Stratospheric transport in a three-dimensional isentropic coordinate model, J. Geophys. Res., 107, 4254, doi: 10.1029/2001JD001313, 2002.

Manney, G. L., Santee, M. L., Livesey, N. J., Froidevaux, L., Read, W. G., Pumphrey, H. C., Waters, J. W., and Pawson, S.: EOS Microwave Limb Sounder observations of the Antarctic polar vortex breakup in 2004, Geophys. Res. Lett., 32, L12811, 2005.

Marchand, M., Godin, S., Hauchecorne, A., Lefèvre, F., and Bekki, S.: Influence of polar ozone loss on Northern mid-latitude regions estimated by a high resolution chemistry transport model during winter 1999-2000, J. Geophys. Res., 108, 8326, doi: 10.1029/2001JD000906, 2003.

McKenna, D. S., Grooß, J.-U., Günther, G., Konopka, P., Müller, R., Carver, G., and Sasano, Y.: A new Chemical Lagrangian Model of the Stratosphere (CLaMS): 2. Formulation of chemistry scheme and initialization, J. Geophys. Res., 107, 4256, doi: 10.1029/2000JD000113, 2002a.

McKenna, D. S., Konopka, P., Grooß, J.-U., Günther, G., Müller, R., Spang, R., Offermann, D., and Orsolini, Y.: A new Chemical Lagrangian Model of the Stratosphere (CLaMS): 1. Formulation of advection and mixing, J. Geophys. Res., 107, 4309, doi:10. 1029/2000JD000114, 2002b.

Millard, G. A., Lee, A. M., and Pyle, J. A.: A model study of the connection between polar and midlatitude ozone loss in the Northern Hemisphere lower stratosphere, J. Geophys. Res., 107, 8323, doi:10.1029/2001JD000899, 108 (D5), 2002.

Morgenstern, O., Lee, A. M., and Pyle, J. A.: Cumulative mixing inferred from stratospheric tracer relationships, J. Geophys. Res., 108, 8321, doi:10.1029/2002JD002098, 2003.

Müller, R. and Günther, G.: A generalized form of Lait's modified potential vorticity, J. Atmos. Sci., 60, 2229-2237, 2003.

Müller, R. and Günther, G.: Polytropic atmospheres and the scaling of potential vorticity, Meteorol. Atmos. Phys., 90, 153-157, doi: 10.1007/s00703-004-0087-6, 2005.

Müller, R., Tilmes, S., Grooß, J.-U., Engel, A., Oelhaf, H., Wetzel, G., Huret, N., Pirre, M., Catoire, V., Toon, G., and Nakajima, H.: Impact of mesospheric intrusions on ozone-tracer relations in the stratospheric polar vortex, J. Geophys. Res., 112, D23307, doi:10.1029/2006JD008315, 2007.
Orsolini, Y. J.: Long-lived tracer patterns in the summer polar stratosphere, Geophys. Res. Lett., 28, 3855-3858, doi:10.1029/ 2001GL013103, 2001.

Riediger, O., Volk, C. M., Strunk, M., and Schmidt, U.: HAGAR - A new in-situ instrument for stratospheric balloons and high altitude aircraft, in: Stratospheric ozone 1999, Proceedings of the fifth European symposium, edited by: Harris, N. R. P., Guirlet, M., and Amanatidis, G. T., Air pollution research report, 73, 727-729, European Commission, 2000.

Spang, R., Remedios, J. J., Kramer, L. J., Poole, L. R., Fromm, M. D., Müller, M., Baumgarten, G., and Konopka, P.: Polar Stratospheric Cloud Observations by MIPAS on ENVISAT: Detection method, validataion and analysis of the Northern Hemisphere winter 2002/2003, Atmos. Chem. Phys., 5, 679-692, 2005, http://www.atmos-chem-phys.net/5/679/2005/.

Steinhorst, H.-M., Konopka, P., Günther, G., and Müller, R.: How permeable is the edge of the Arctic vortex - Model studies of the winter 1999-2000, J. Geophys. Res., 110, D06105, doi:10.1029/ 2004JD005268, 2005.

Streibel, M., Rex, M., von der Gathen, P., Lehmann, R., Harris, N. R. P., Braathen, G. O., Reimer, E., Deckelmann, H., Chipperfield, M., Millard, G., Allaart, M., Andersen, S. B., Claude, H., Davies, J., De Backer, H., Dier, H., Dorokov, V., Fast, H., Gerding, M., Kyrö, E., Litynska, Z., Moore, D., Moran, E., Nagai, T., Nakane, H., Parrondo, C., Skrivankova, P., Stübi, R., Vaughan, G., Viatte, P., and Yushkov, V.: Chemical ozone loss in the Arctic winter 2002/2003 determined with Match, Atmos. Chem. Phys., 6, 2783-2792, 2006, http://www.atmos-chem-phys.net/6/2783/2006/.

Tilmes, S., Müller, R., Grooß, J.-U., Höpfner, M., Toon, G. C., and Russell, J. M.: Very early chlorine activation and ozone loss in the Arctic winter 2002-2003, Geophys. Res. Lett., 30, 2201, doi: 10.1029/2003GL018079, 2003a.

Tilmes, S., Müller, R., Grooß, J.-U., McKenna, D. S., Russell, J. M., and Sasano, Y.: Calculation of chemical ozone loss in the Arctic winter 1996-1997 using ozone-tracer correlations: Comparison of Improved Limb Atmospheric Spectrometer (ILAS) and Halogen Occultation Experiment (HALOE) results, J. Geophys. Res., 108, 4045, doi:10.1029/2002JD002213, 2003b.

von Hobe, M., Grooß, J.-U., Müller, R., Hrechanyy, S., Winkler, U., and Stroh, F.: A re-evaluation of the $\mathrm{ClO} / \mathrm{Cl}_{2} \mathrm{O}_{2}$ equilibrium constant based on stratospheric in-situ observations, Atmos. Chem. Phys., 5, 693-702, 2005,

http://www.atmos-chem-phys.net/5/693/2005/.

WMO: Scientific assessment of ozone depletion: 2006, Global Ozone Research and Monitoring Project-Report No. 50, Geneva, Switzerland, 2007. 